\title{
Development of An Analysis Capability for The National Transportation System
}

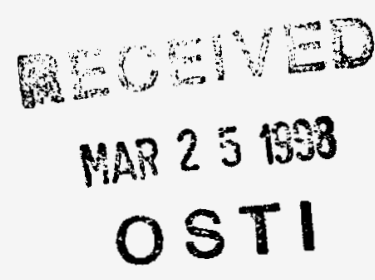

Doug Anson \& Ralph Nelson

In support of the Department of Transportation's National Transportation System (NTS) Initiative, LANL is investigating the development of a NTS analysis capability. This report describes the NTS Initiative, characteristics of the NTS problem, an analysis capability based on a "TRANSIMS-like" approach, data requirements, and a scenario for a prototype demonstration.

\subsection{Introduction}

\subsection{Purpose \& Objectives}

The purpose of this report is to examine the Department of Transportation's (DOT) National Transportation System (NTS) Initiative, to document what has been learned, and to outline a National Transportation Network Analysis Capability (NTNAC) based on a "TRANSIMS-like" approach.

This study was conducted over a two month period at the end of FY 1997. The scope of the effort was carefully defined to accomodate the short time horizon and to provide focus to a very lange analytical problem. Our objectives were to:

1. Define the NTS and the NTS problem;

2. Identify problem characteristics;

3. Describe an analytical solution based on the TRANSIMS approach;

4. Identify data requirements and availability;

5. Develop criteria for a scenario to be used in a prototype demonstration; and

6. Select a scenario for the prototype demonstration.

DistRUBUTION OF THIS DOCUMENT is UNLIMTED th
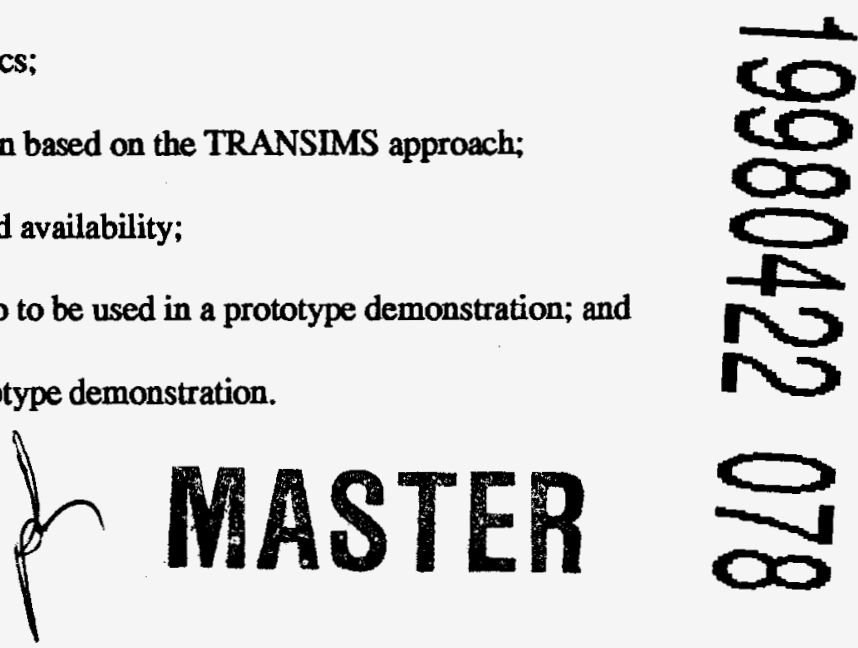


\subsection{Executive Summary}

The Department of Transportation does not have the ability to view and analyze the Nation's transportation system in its entirety as a single integrated, intermodal system. These are DOT's own words and they are a description of the fundamental NTS problem.

The National Transportation System (NTS) consists of the highway, rail, air, waterway, and pipeline infrastructures. The DOT has established an NTS Initiative that has, at the core of its Technical Process objectives, the National Transportation Network Analysis Capability (NTNAC). The NTNAC is envisioned to be a set of analytical tools that are used to assess the performance of the system.

The tools required to analyze the system must be capable of quantitatively addressing national issues such as transportation support of national economic development, changes needed to ensure the flow of international trade, congested travel in dense intercity corridors, and the impact of oil dependency, shortages and price increases on system efficiency. Advances in computational technology and dynamical systems theory have only recently resulted in tools which permit the analyst to peer inside complex metropolitan transportation systems and begin to understand urban travel dynamics. This report documents initial efforts to take these technologies and tools to the next level - to the next transportation system hierarchy of dynamically coupled metropolitan areas, airports, seaports, rail and highway intermodal nodes, and the national multimodal links that connect them.

Characterization of the transportation issues leads to the conclusion that all national questions belong to one of the following classes of problems: those that require steady state, quasi-steady state, or transient system analyses. The approach taken by LANL's TRANSIMS project in its representation of metropolitan transportation systems addresses these problem classes. Adoption of TRANSIMS' conceptual framework and application of many of its complex adaptive systems algorithms will provide a firm basis for the NTNAC.

The resources and effort required to build an integrated set of dynamically consistent NTNAC tools is a monumental effort. The data, algorithms, hardware, software and mutlidisciplinary skills that must be brought together are considerable. This is the beginning (we hope) of a long term research and development project that has the potential to make significant contributions to the transportation, complex systems, and simulation sciences as well as to the DOT's analytical capabilities. 


\section{DISCLAIMER}

This report was prepared as an account of work sponsored by an agency of the United States Government. Neither the United States Governmeat nor any agency thereof, nor any of their employees, makes any warranty, express or implied, or assumes any legal liability or responsibility for the accuracy, completeness, or usefulness of any information, apparatus, product, or process disclosed, or represents that its use would not infringe privately owned rights. Reference herein to any specific commercial product, process, or service by trade name, trademark, manufacturer, or otherwise does not necessarily constitute or imply its endorsement, recommendation, or favoring by the United States Government or any agency thereof. The views and opinions of authors expressed herein do not necessarily state or reflect those of the United States Government or-any agency thereof. 


\subsection{NTS Problem Definition}

In this section we define the NTS problem from DOT's policy perspective. In section 4.0, we will extend the definition to the technical process level.

\subsection{Background}

In 1991 the Intermodal Surface Transportation Act (ISTEA) was passed. Its overall objective is the improved performance of statewide and metropolitan transportation systems through preservation of existing facilities and equipment, operational enhancements to improve the efficiency and environmental impacts of the system, and capacity enhancements to improve the effectiveness of the intermodal system. It also encouraged intermodalism as a way to obtain optimum yield from existing resources, rather than relying solely on system expansion.

It is in the National interest to encourage and promote the development of transportation systems embracing various modes of transportation in a manner that will serve all areas of a State efficiently and effectively.

As a result of ISTEA, state and metropolitan planning organizations (MPO) are now required to address issues related to infrastructure, congestion, and air quality in more precise and quantitative terms. In recognition of these new requirements, the Federal Highway Administration wrote,

Existing transportation planning models and procedures [must] identify congestion problems and possible corrective strategies and ... measure performance of implemented strategies at the micro level.

States with highly urbanized regions agreed and added that "existing tools were not adequate and need to be completely replaced."

The need for new analytical strategies based on a "micro level" examination of traffic caused LANL to propose the Transportation Analysis and Simulation System (TRANSIMS). After four years of development under DOT's Travel Model Improvement Program, TRANSIMS has demonstrated the capability to provide a regional-level, microscale system representation that allows unification of issues in the areas of regional analysis, traffic engineering, and environmental impact analysis through the application of advanced computational and analytical techniques.

During the years following the passage of ISTEA, DOT decided that it must move beyond the regional and state focus and promote an efficient transportation system at the national level. In December 1993 Secretary of Transportation Pena announced his intention to launch the NTS Intiative. His intent was to

'Tie America Together' [through the development of] a new National Transportation System that integrates all modes and emphasizes connections, choices, and coordination of transportation services.... 
FUNDAMENTAL NTS PROBLEM:

Integrated, intermodal NTS analytical tools do not exist
Since Secretary Pena's announcement DOT has solicited the assistance of other governmental agencies, private industry and academia to help define the NTS concept and identify the analytical capabilities necessary to support the effort.

\subsection{DOT's Need}

The DOT is seeking to better understand the capabilities of the nation's transportation system because of the role it plays in proposing and carrying out legislative, regulatory, and federal transportation program management actions. Questions like, "How well does the system serve the people?" and "What is needed to meet the public's expectations?" are fundamental, but currently very diffucult to answer. Surveys are typically used but they are time consuming, expensive, and provide only qualitative information. What is needed is a quantitative approach which integrates all data in a total system framework.

The transportation system is a means to an end - a way to move people and goods from point $A$ to point $B$ in order to perform personal and business activities. Travelers and shippers view it as a large, complex multi-modal and intermodal network. Network and transportation infrastructure efficiency is measured in terms of how well it meets their needs. Time, cost, distance, safety, and security are the usual measures of system efficiency at the individual user and private establishment level. Contribution to economic, social, and environmental goals are important measures of transportation system effectiveness at the public sector level.

The fundamental problem is that the analytical tools required to evaluate the national transportation system as a whole do not exist. The DOT's current capabilities are confined within modal limits by the modal orientation of the data and analytical tools. The DOT admits that,

passenger and freight movements over more than one mode often find connections to be more difficult and less efficient than they might be.... [We have] no way to aggregate [modal segmented data] for origin to destination journeys or shipments.

The Department still does not have the ability to view and analyze the Nation's transportation system in its entirety as a single integrated, intermodal system. Preoccupation with modal subsystems often results in prejudging solutions to transportation problems and, thereby a failure to realize the greatest payoff from scarce resources."

Therefore, what is required is a "national measurement and analytical capability... [which is] designed and used in a setting that recognizes and complements existing public and private activities."

\subsection{NTS Initiative Defined}

The NTS consists of the highway, rail, air, waterway and pipeline infrastructure as well as the carriers that traverse these networks. DOT views the NTS Initiative in a larger context, however. They view it as a process or framework in which to manage.

A CONCEPT that recognizes interaction between the Nation's goals and the components of the nation's transportation system. 
A METHOD of looking at the total transportation system and its effect on social, economic and environmental systems.

An INSTITUTIONAL FRAMEWORK for partnering among the federal government, state and local agencies, the private sector and general public.

A TECHNICAL PROCESS which uses analytical and measurement tools to build the capability to assess performance, identify issues, evaluate policy options, and develop strategies.

A STRATEGIC PLANNING STRUCTURE for future development of the nation's transportation system.

The technical core of the NTS Initiative lies in the "Technical Process" and is called the National Transportation Network Analysis Capability (NTNAC). It is envisioned to be a set of analytical tools that are used to assess the performance of the system from a customer perspective. Assessment includes determining the current level of performance, identifying problem areas, and testing alternative solutions.

\subsection{NTS Goals}

GOAL OF THE NTS:

Optimize the contribution of each mode to the overall transportation system
The goal of the NTS is to reap the potential benefits of intermodalism by optimizing the contribution of each mode to the overall transportation system, thus reducing the cost and improving the quality, cost, timeliness, and safety of passenger and freight transportation. Specific potential contributions of intermodalism include:

- Increasing economic productivity and efficiency and maintaining the Nation's competitive position in an increasingly global economy.

- Using the Nation's transportation infrastructure more efficiently. Maximizing utilization of the transportation system by reducing the burden on over-stressed infrastructure components and shifting it to infrastructure with excess capacity. Leveraging the relative strengths and efficiencies of all the transportation modes.

- Generating higher returns from public and private infrastructure investments.

- Improving mobility, service, convenience, and the general quality of life.

- Reducing energy consumption, and contributing to improved air quality and environmental conditions.

\subsection{NTS Requirements}

DOT has focused its NTNAC development efforts in two areas. First, they developed a list of national transportation issues. Second, they identified system performance measures or, as they call them, "performance indicators." These issues and system measures are important to our understanding of the NTS problem and must be incorporated into any NTNAC solution. 


\subsubsection{NTS Issues to be Addressed}

NATIONAL TRANSPORTATION ISSUES:

Range from truck weight to national economic expansion

\section{NTS PERFORMANCE MEASURES:}

DOT has identified $40+$ system performance measures, or "indicators"
The NTS issues provided by DOT are listed below.

- Overall efficiency of the Nation's transportation system.

- Ability of the system to support national economic development and expansion.

- Opportunities to improve intermodal connections on intercity freight and passenger travel.

- Integration of metropolitan travel into the national network.

- Approaches to addressing congested travel in dense intercity corridors.

- Regional changes to the system needed to ensure the flow of international trade resulting from NAFTA, GATT, and other agreements.

- Effect of changes in trade flows on port capacity and supporting highway and rail capacity and service.

- Effect of advances in transportation technology on overall system performance.

- Impact of oil dependency, shortages and price increases on system efficiency.

- Effects of changes in user charges and fuel taxes.

- Systematic effects of changing truck size and weight regulations.

- Changes in the system to improve national environmental quality.

- Impact of changes in safety.

- Impact of natural disasters and military emergencies.

\subsubsection{NTS Performance Measures - "Indicators"}

The DOT has identified a set of NTS performance indicators. These are "signals" of system performance which are national in scope, multimodal. and indicate that the system is functioning well or, alternatively, provide clues to follow-on analysis for problem areas or unexpected results. DOT has decided to use the term "indicators" rather than "measures" due to state level concerns about the relationship between "performance measures" and federal funding. While we might consider this mostly semantics, DOT claims that the difference lies in one's "orientation" - whether it be a policy orientation or a performance orientation.

Performance Indicators will be used in policy planning and decision making to indicate conditions, problems, or other results that would enhance our understanding of how well the transportation system is performing nationally; to monitor the effectiveness of regulatory and program management decisions; and to suggest directions for more detailed investigation of emerging issues.

It is irrelevant how these quantities are used (i.e., to develop policies vs. evaluate performance). From a quantitative, or modeling. perspective there is no difference between an indicator or measure.

NTS performance indicators are grouped into five areas: freight, passenger, defense and readiness, system safety, and system environmental indicators. 
Freight System Indicators. These performance indicators will be disaggregated by bulk, break bulk and package, and further disaggregated by international, intercity and local, and commodity depending on the particular study questions.

- value of goods moved

- speed of movements, based on direct distance from origin to destination (not actual path distance)

- standard deviation of speed of movements

- dwell time during movements

- time delayed due to incidents and congestion

- cost of shipment

- loss due to theft and accident

- surveys of service adequacy

Passenger System Indicators. These performance indicators will be disaggregated by market, trip purpose, and socio-economic category depending on the particular study questions.

- speed of movements, based on direct distance from origin to destination (not actual path distance)

- standard deviation of speed of movements

- out-of-vehicle time during movements involving a for-hire link

- average hours per day devoted to travel

- time delayed due to accidents, breakdowns, and congestion

- incidents of assault and theft

- population within $1 / 4$ mile of scheduled public transportation

- population within 20 miles (or $1 / 2$ hour) of access to intercity transportation

- number of cities without scheduled, daily intercity for-hire service, by population category

- number of cities without direct access to port of embarkation for international service, by population category

- share of US overseas passengers who can enter/exit country directly from their home metropolitan area

- surveys of service adequacy

\section{Defense \& Readiness Indicators.}

- elapsed time to deploy defense force assets from origin installation through loadout air or sea port of embarkation

- total person-day and ton-day delay in defense deployment profile times attributable to transportation system deficiencies 
- impact of transportation system delays on mission of deployed defense force (added days of combat, added casualties, increases in retrograde movement of the forward line of own troops)

System Safety Indicators. These performance indicators will be aggregated by multimodal trips and disaggregated by individual modes.

- number of transportation system deaths

- lifetime risk of death in system use compared to other causes

- number of transportation system serious injuries

- lifetime risk of serious injury in system use compared to other causes

- health cost of injuries

- transportation accident property damage and loss

\section{System Environmental Indicators.}

- total nonrenewable (carbon-based) energy consumed in the operation of the transportation system

- total nonrenewable (carbon-based) energy consumed in the construction and maintenance of the transportation system

- air quality nonattainment areas where transportation is the principa problem

- population exposed to greater than threshold level of airborne emissions from transportation sources

- tons of carbon monoxide generated by transportation

- tons of volatile organic compounds (hydrocarbons) generated by transportation

- tons of particulate matter generated by transportation

- tons of nitrogen dioxide generated by transportation

- tons of carbon dioxide generated by transportation

- deaths attributable to transportation-generated air and water pollution

- health costs attributable to transportation-generated air and water pollution

- net loss of wetlands to transportation uses

- population exposed to greater than threshold noise from transportation sources

- number of serious hazardous materials incidents

- number of serious incidents/ton-miles of hazardous materials transported

\subsection{Technical Characteristics of the NTS Problem}

After having defined the NTS problem from the DOT's policy perspective in section 2.0, we further define the NTS from the perspective of a technical process. In this section we will examine some of its technical characteristics. By "technical characteristics" we mean three things: the classes of problems implied by DOT's definition of the NTS, 


\section{NTS CLASSES OF PROBLEMS}

- Steady State - Quasi-Steady State

- Transient attributes of the NTS issues listed in section 3.2.1, and attributes of the performance indicators listed in section 3.2.2.

\subsection{NTS Problem Classes}

\subsubsection{Classes of Problems}

The NTS issues provided by DOT suggest certain classes of problems based on underlying NTS, or system, dynamics. These problem classes are best identified by the types of analyses required to examine the sets of issues they represent: steady state, quasi-steady state, and transient. Within the study of dynamical systems, these are classical problem types. They are a valid representation for the underlying perspectives necessary to identify a feasible approach to the NTS analysis problem.

The specification of a problem class for an individual issue further depends on the time and spatial horizons of interest. Therefore, a problem class can be described as a function of three elements:

$$
\begin{array}{r}
\text { problem class }=\mathbf{f} \text { (issue time horizon, issue spatial horizon, } \\
\text { dynamic variables needed to address issue) }
\end{array}
$$

Steady state problems are those that can be addressed using constant dependent system state variables, and the system representation is often accomplished by using simple heuristic models that capture the "behavior" of the system (see Appendix A). Quasisteady state refers to those issues requiring examination using rate related dependent state variables. Often the same heuristic models developed via the steady-state approach are applied to a quasi-steady analysis. Transient problems are those that must be addressed using a system representation based on both transient dependent state variables and transient heuristic models. Because transient heuristic models are generally nonexistent in any field of study, this requires the identification and representation of the underlying physics within what is often called a "microscope simulation."

It should be realized that in many fields, the problems have been so monumental regarding a system's dynamics that the analyst has had little choice but to make steady-state or quasi-steady assumptions. It is only in recent times that computational power has grown to the point where we can begin to investigate systems exhibiting "complex" dynamic behavior. We will further discuss the issue of complexity in section 4.2.

\subsubsection{Examples of Problem Classes}

The issue concerning the "Ability of the system to support national economic development and expansion" might be viewed as either a steady state or quasi-steady state problem. If the analyst's concern is at the national level (e.g.. Gross National Product or employment level as a function of NTS Performance Indicators) during the next decade, he is likely to make assumptions like the following: fix the population size (dependent demand state variable) at years 0 and 10 , and hold regional populations, national highway and intermodal facility locations (independent supply state variables) constant throughout the decade. This issue can now be addressed using a steady-state model representation due to the combination of long time horizon, large spatial coverage and constant dependent and independent system state variables. If the analyst was confident 
NATIONAL ISSUES \& NTS PERFORMANCE INDICATORS

Most require an understanding of system dynamics about his national population estimates, but unsure about the regional level population and intermodal facility dynamics, he would have to employ a quasi-steady state system which represented the transient behavior of the independent state variables.

An example of an issue falling into the transient problem class is the "Impact of natural disasters and military emergencies." In a natural disaster, the time horizon is short and the location is likely to be within a very specific region. A dependent system state variable of interest might be system throughput. Independent state variables include facility capacity and demand. This is clearly a transient process - all of the state variables cited here, both dependent and independent, undergo rapid changes throughout the duration of the scenario. A transient analyis is required - the analyst runs the risk, for example, of overlooking critical bottlenecks if he employs a time averaging (quasi-steady state) analysis.

\subsection{Attributes of NTS Issues \& Performance Indicators}

By "attributes" we mean conceptual and network-based system characteristics. These include the conceptual supply, demand, planning, and execution characteristics to be described in section 4.1, and the effects on system throughput in the form of traffic flow, congestion, link and node capacities, time delays, distances, costs, modal preferences, etc.

\subsubsection{Issue Attributes}

Overall NTS efficiency is a function of performance indicators. The weight assigned to each indicator depends on the study question, or one's perspective. The ability of the NTS to support national economic expansion and flow of international trade is related to transportation supply and demand relationships. For example, improving the nation's north-south interstate highways will support and enhance the increased trade with Mexico and Canada resulting from the North American Free Trade Agreement (NAFTA). Effect of trade flow changes on port capacity, and highway and rail capacity focuses on changes in freight traffic flow and methods for increasing or rerouting this flow to achieve desired throughput. Improving intermodal connections refers primarily to reducing the delay associated with transferring from one mode to another. Integration of metropolitan travel into the national network implies identification and connection of multimodal traffic flow across metropolitan boundaries from/to the national network. A primary technical concern is connecting urban and national networks of different fidelity. Congested travel in intercity corridors suggests traffic flow and capacity analyses similar to those being studied within metropolitan areas (e.g., using TRANSIMS). Impact of fuel shortages, taxes, price increases and other user charges all pertain to traveler cost functions and the effect they have on individual traveler and business goal achievement. The effects of truck size and weight regulations suggest changes in traffic flow, roadway deterioration, incidents, and air quality as well as the impact these have on demand (e.g., use of alternative modes of transportation). Opportunities to improve national environmental quality requires analysis of traffic congestion, facility location, and the relative impact each mode, and its supporting infrastructure, has on land, air and water resources. Changes in safety effect throughput and travel costs as well as traffic incidents (e.g., federally mandated maximum speed limits). The impact of natural disasters and military emergencies requires analysis of sudden changes in link and node capacities, and unusual demand for alternative facilities as traffic is rerouted. 


\subsubsection{Performance Indicator Attributes}

The DOT has specified over 40 performance indicators - these mutliply quickly depending on the level of disagreggation required. Because of their large number, and for reasons having to do with differences between traditional transportation analysis and our solution approach (section 4.0), these indicators are categorized according to inherent static and dynamical characteristics. Static attributes refer to indicators whose values remain constant over most national transportation issue time horizons. Dynamic indicators are those whose values may vary during a study question's time horizon, or are dependent on dynamic transportation measures like traffic flow, congestion, intermodal transfer time, etc. Those marked with an asterisk fall into either category depending upon their method of calculation.

\section{Static Performance Indicators.}

- value of goods moved*

- cost of shipment *

- incidents of assault and theft

- population within $1 / 4$ mile of scheduled public transportation

- population within 20 miles (or $1 / 2$ hour) of access to intercity transportation

- number of cities without scheduled, daily intercity for-hire service, by

population category

- number of cities without direct access to port of embarkation for international service, by population category

- share of US overseas passengers who can enter/exit country directly from their home metropolitan area

- lifetime risk of death in system use compared to other causes*

- lifetime risk of serious injury in system use compared to other causes*

- net loss of wetlands due to transportation uses

- population exposed to greater than threshold noise from transportation sources*

- surveys of service adequacy 


\section{Dynamic Performance indicators.}

- speed of movements

- standard deviation of speed of movements

- dwell time during movements

- time delayed due to incidents and congestion

- out-of-vehicle time during movements involving a for-hire-link

- average hours per day devoted to travel

- number of transportation system deaths

- number of transportation system serious injuries

- health cost of injuries

- transportation accident property damage and loss

- all environmental indicators, except the two listed above

- elapsed time to deploy defense force assets...

- total person-day and ton-day delay in defense deployment profile times ...

- impact of transportation system delays on mission of deployed defense force . .

\subsection{The TRANSIMS Approach to the Metropolitan} Transportation Problem

\section{TRANSIMS}

\section{CONTRIBUTIONS TO THE} TRANSPORTATION COMMUNITY:

A conceptual framework and application of CAS at the urban system level
After having described the NTS problem in sections 2.0 and 3.0, we briefly describe some of the fundamental concepts provided by TRANSIMS. In section 5.0 we will apply these concepts in a NTNAC solution.

TRANSIMS introduced two concepts to the transportation community in 1993. One was an analytical decomposition of large scale transportation system dynamics and the other was the application of complex adaptive systems (CAS) science to metropolitan transportation system analysis. Together, they provided a new way of analyzing large scale transportation problems - at least at the metropolitan level. Prior to this, the transportation community relied on the traditional Urban Transportation Modeling System, or the "4 Step Method." In general, the TRANSIMS' concepts did away with many of its long standing static, linear, and deterministic assumptions. Instead of a top-down, analytical modeling approach largely based on fitting statistical models to static or averaged empirical data, TRANSIMS constructed a representation from the bottom-up. In 
this approach global traffic dynamics emerge from local interactions among individual travelers and their environment. In sections 4.1 and 4.2 we briefly describe both concepts.

\subsection{A Conceptual Framework - Analytical Decomposition of Large Scale Transportation System Dynamics}

The TRANSIMS project introduced a conceptual framework based on a new partition of the transportation problem. It decomposed the problem into the five modules shown in figure 1: Supply, Demand, Plan, Execute, and Analysis. This decomposition separates the multiple time scales and local decision making processes inherent to the problem. In addition to the advantages described in the next section, this partition improves both computational efficiency and understanding of a large, interconnected transportation system.

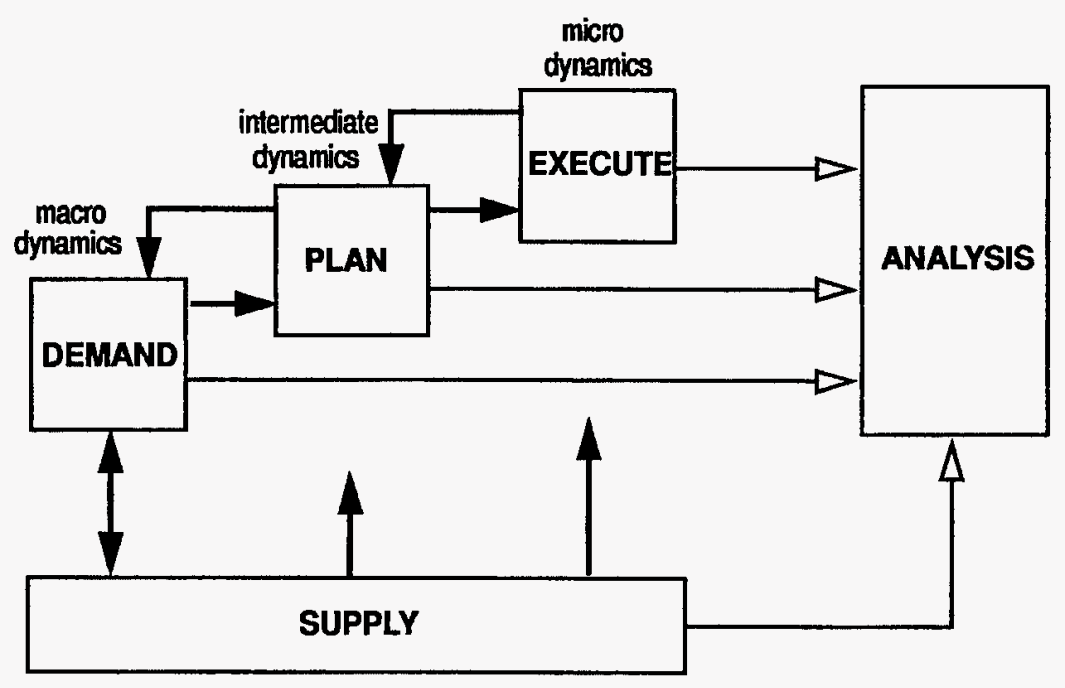

Figure 1. Conceptual Framework of Large Scale Transportation System Dynamics

This framework provides insight into the underlying dynamics of any large scale transportation system. Without this understanding, transportation planners and policy makers cannot, for example, accurately assess the impact of new facilities, technology, or natural disasters on the overall efficiency of the system. Each module is described generically below. Specific application of each to the NTS is described in the section 5.2.

\subsubsection{Supply}

The Supply component is the transportation infrastructure, to include carriers and intermodal transfer facilities, upon which the users travel. It is a source of input data to the Plan and Execute modules, and interacts with the Demand module over long time scales according to economic supply and demand principles. 


\subsubsection{Demand}

The Demand component is the "Who, What, When \& Where" of the transportation problem. It addresses "who" the users of the system are: individuals, households, businesses, commodities, military, etc; "what" activities the users need to perform: work, shopping, delivery, manufacturing, deployment, etc; "when" the activities need to be performed; and "where" the activities need or can be performed. This module is a source of input to the Plan component, and interacts with the Supply module over long time scales according to economic supply and demand principles.

\subsubsection{Plan}

The Plan component is the "How" of the transportation problem. It addresses "how" the users plan to traverse the system over intermediate time scales on a low fidelity network provided by the Supply component. This includes determination of routes and modes, at the level at which planning actually occurs (e.g., individual traveler, commercial fleet schedulers, and central military planners), based upon assumptions concerning congestion, link speeds, intermodal transfer times, and travel goals and mode preferences. This module is a source of input to the Execute component which, in-turn, is an input source to the Plan component. It is within this plan-execute-replan iterative feedback process that critical real-world intermediate dynamics are represented.

\subsubsection{Execute}

The Execute component is the "What Happened' of the transportation problem. It addresses "what happened" when the travelers attempted to execute their travel plans under micro time scales on a high fidelity network provided by the Supply component. "What" each traveler experiences usually differs from what is assumed in the planning function. For example, a travel plan may be based upon traveling the speed limit along certain links. Unexpected congestion may occur due to other travelers making similar assumptions resulting in slower than expected link traversal times and failure to satisfy plan travel time goals (e.g., a late delivery). This new information is "learned" by the traveler in the form of iterative feedback to the Plan module and provided to the trip plan function for replanning. The Execute component is a source of input for both the Plan and Analysis components.

\subsubsection{Analysis}

The Analysis component is the "Why and What if" of the transportation problem. It enables the analyst to address "why," for example, is the throughput of the system so low as evidenced by the slow speed of many commodity shipments, the long out-ofvehicle time for certain populations, and other suboptimal performance indicators? "What if" an efficient truck-rail intermodal facility were built at location X? Would these same performance indicators improve, or would this facility become a bottleneck resulting in even less throughput? If these indicators initially improve, will they eventually return to their original values, or possibly worse values, due to user learning and adjustment? This is the analyst's tool for evaluating system performance and testing alternative solutions.

\subsection{Complex Adaptive Systems}

Our understanding, or lack of understanding, of many phenomena in nature may be due to their complex and adaptive behavior. In the last 15 years people from a variety of disciplines have come together to study this behavior in physical and social systems. Ideas 
surrounding intelligent agents, goal seeking behavior, agent-agent and agent-environment interaction, adaptation and emergence are being studied under the headings of Complexity, Sciences of Complex Systems, and Complex Adaptive Systems. Many of these ideas have already been tested and applied successfully to metropolitan transportation systems by TRANSIMS. Many are applicable to the NTS as well. In this section we pose a fundamental question concerning the mystery of complex systems. We then describe a Complex Adaptive System (CAS) and its application in TRANSIMS.

At a recent Santa Fe Institute lecture, a fundamental question was asked,

How do large networks with

- simple components,

- limited communication among components,

- no central control, and

- simple rules of operation

give rise to complex behavior?

What is a "complex system?" A system can be considered complex if its collective behavior is predominated by interactions among the components, irrespective of the detail associated with either the system's internal structure or its components. Adaptation refers to changes in the system's interaction strategies. The ability to adapt permits the complex system, and possibly each component, to improve its performance. The critical idea surrounding the emergence of complex behavior is the system's ability to create new structures and properties; i.e., the potential system components possess to generate global structures purely from local interactions.

In TRANSIMS the critical components, or intelligent agents, are the individual travelers. "Intelligence" is the ability to make decisions on the basis of rules, and to modify those rules in the presence of new information. Individual traveler trip plans are generated from routing algorithms based on time optimization goal functions, or a set of rules. Function parameter values, like link speeds, are established based on previous experience (i.e., agent-link interactions) and updated after each new experience in TRANSIMS' iterative plan-execute-replan feedback process. An important global system behavior that emerges from this adaptive process is collective travel demand - the sum total of the transportation users desires to use specific facilities at specific times. The ability to generate emergent behavior, and trace it back to its nonlinear, dynamic roots, is what was lacking in the transportation community before TRANSIMS was built.

How does one represent agents, agent-agent interaction, adaptation and emergence? What mechanism, or algorithmic engine, can produce such high order systems? Certainly not the analytical approaches or models still used by most of the transportation community. Simulations are required. Large scale (complex) transportation systems can only be studied through computer simulation due to its capacity to handle the mag- 
nitude of parallel decision making and interaction processes and, perhaps most importantly, to generate relations that are not explicitly encoded.

The CAS and simulation research communities are actively seeking a better understanding this new science: the notions discussed above, a firm mathematical foundation, and unifying priciples which span the range of natural phenomena exhibiting complex and adaptive behavior.

\subsection{Application of the TRANSIMS Approach to the NTS Problem}

TRANSIMS' contributions to the metropolitan transportation problem are novel and relevant. Relevancy is evident by the fact that it is gaining acceptance within the transportation community. In fact, one of the project's underlying goals is to change the way transportation researchers and planners analyze transportation problems in general. If the TRANSIMS approach truly represents a fundamental change in transportation analysis, it should also be applicable at other transportation system levels as well.

In section 5.1, we begin by summarizing the TRANSIMS concepts which extend to the NTS. We then discuss the ultimate representational objective of our NTS solution in section 5.2. Sections 5.3 and 5.4 describe the utility of TRANSIMS' conceptual framework and CAS idea, respectively, to the NTS problem.

\subsection{Summary}

A "TRANSIMS-like" solution to the NTS problem can be summarized as follows:

- The underlying conceptual framework - the analytical decomposition of large scale transportation system dynamics - introduced by TRANSIMS, is the same framework from which to analyze the NTS.

- National level issues will cause the "front-end" of the conceptual framework (Supply-Demand-Plan, and the feedback processes among them) to be exercised more than the the Execution component. This is in contrast to the shorter term metropolitan issues addressed by TRANSIMS.

NTS:

A hierarchical CAS comprised of individual CAS(s) at each node
- Applying the descriptive definition of a Complex Adaptive System (CAS) provided in section 4.0, both metropolitan transportation systems and the NTS are CAS(s).

- TRANSIMS' single CAS representation of an urban region must be extended to a hierarchical set of CAS(s). Each modal system of the NTS is, in itself, a CAS; these "sub-CAS(s)" are coupled physically at network nodes and informationally through user multimodal planning processes.

- NTS network fidelity within the Execute component must be variable - and possibly dynamic to account for boundary conditions between high fidelity nodes and lower fidelity links, and national issues which involve sudden changes in link densities from free flow traffic to congestion. 


\section{NTNAC OBJECTIVE:}

Represent the dynamic intermodal movement of goods and people
- Coupled nonlinear dynamic systems, such as those embedded in TRANSIMS and the NTS, may exhibit behavior that can only be identified through the study of their integrated representation.

\subsection{Objective.}

A fundamental difference between TRANSIMS and the transportation community's "4 Step Method" is representation of system dynamics. While TRANSIMS explicitly addresses this phenomenon, the "4 Step Method" essentially assumes it away. Given the recent contributions of TRANSIMS and the preponderance of national issues and performance indicators requiring dynamic analyses of intermodal systems, the NTNAC solution must have the dynamic intermodal movement of goods and people as its principle representational objective.

Dynamic traffic flow is required for certain classes of problems that cannot be satisfactorily addressed using steady state methods. These problems include complex intercity congestion dynamics beginning at urban nodes and spilling back onto intercity links; increasing intermodal demand and facility stress due to the proliferation of Just-In-Time policies; safety issues concerning the use of Long Commercial Vehicles; and environmental issues concerning oversized and poorly regulated Mexican trucks operating within the U.S. under NAFTA. All of these questions are time and space dependent. They involve time and space constraints, time delays, variable carrier velocities, uncertain intermodal connections and transfers, driver reaction times, carrier acceleration profiles, etc. Traditional transportation modeling and analysis techniques are based on steady state, or equilibrium, models built and validated to reproduce data collected over very short time intervals; this data is essentially a "snapshot," or an instantaneous view, of a portion of the system under study. Thus, only a subset of the DOT specified performance indicators can be addressed. ANTNAC solution must explicitly address both the dynamic and static NTS performance indicators.

The generation of dynamic traffic flow can only be accomplished if one goes to the causal level - the level at which travel decisions are made. Individual establishments (households, businesses and governments) make travel decisions based on travel goals, limited knowledge of the transportation system, and experience. These travel decisions take the form of travel plans. As travelers and commodity shippers attempt to execute their plans, they find themselves having to conform to both the constraints imposed by the physical transportation infrastructure as well as those created by other travelers attempting to execute their own plans. It is here, where travelers, shippers, the military, etc. interact, and learn to adapt over time, that macro level dynamic travel flows emerge.

Only one other group has addressed the NTS analysis problem at national spatial and temporal scales. This, however, is yet another static approach - one based on the collection of supply and demand data and use of Geographic Information Systems to view the data from many different perspectives. While this is a critical capability, it ignores those transportation issues that require knowledge of transportation dynamics. 


\subsection{Application of TRANSIMS' Conceptual Framework: The Analytical Decomposition of a Large Scale Transportation System}

The NTS can be decomposed into the conceptual framework described in section 4.1.

This decomposition captures the dynamics, goal-seeking behavior, adaptivity, and multiple time and spatial scales of the system.

A general description of the conceptual framework, the decomposition of large scale transportation systems into five components, is found in section 4.1. Here we discuss how the NTS fits in this framework. We begin with figure 2's extension of TRANSIMS' (current) single mode and single user (individual automobile travelers) metropolitan transportation system. Recall that from a "birds-eye" view, urban areas are simply nodes within the larger NTS. As one "flys in" closer, the urban nodes become the highly detailed urban networks addressed by TRANSIMS. The NTS network structure,

TRANSIMS' DECOMPOSITION OF A TRANSPORTATION SYSTEM:

Applicable to the NTS and metropolitan systems then, is hierarchical - with urban, and other nodal, dynamical systems embedded within the national system.

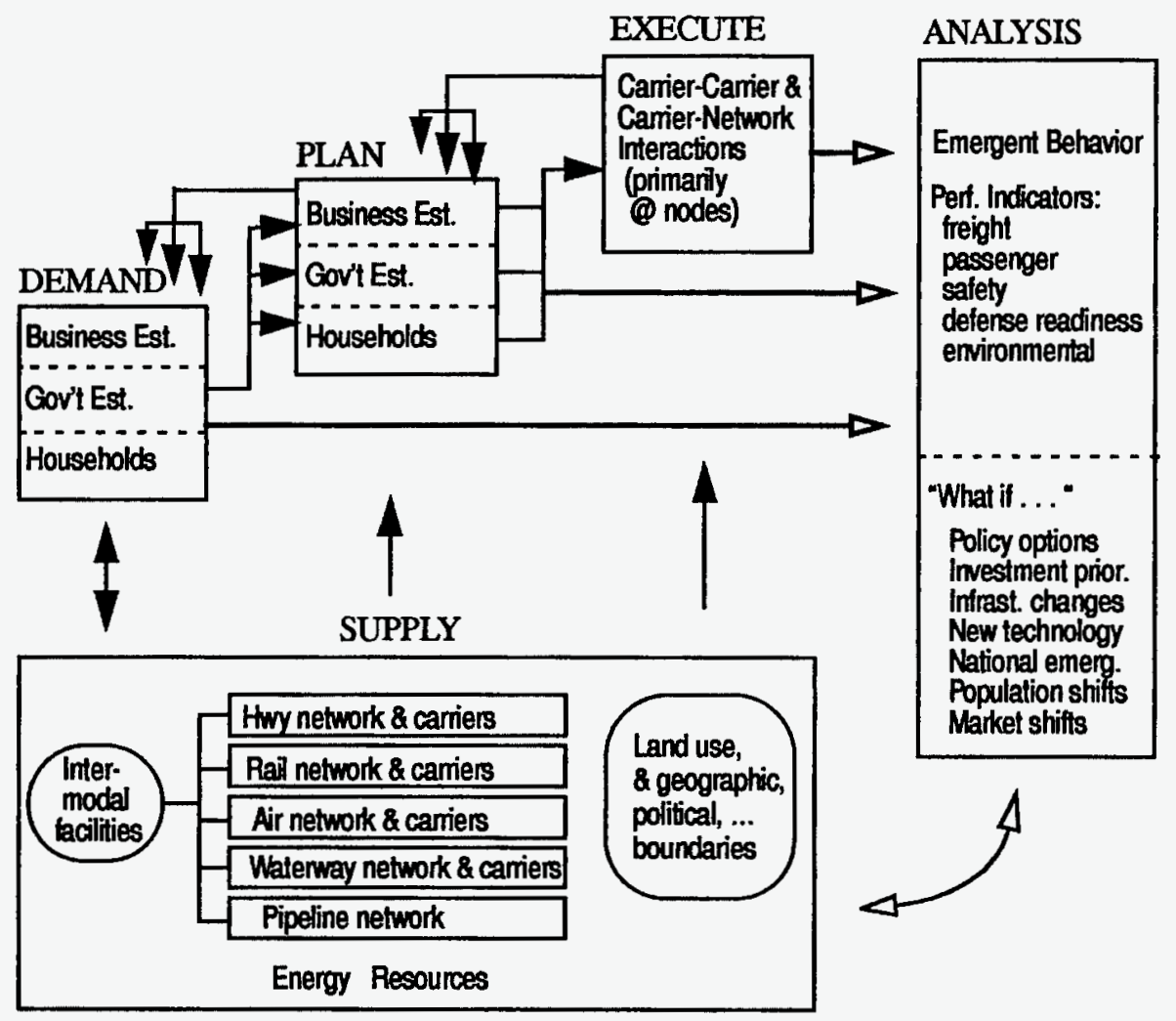

Figure 2. Extending TRANSIMS' Conceptual Framework for the NTS

\subsubsection{Supply}

The Supply component provides a network based representation of the NTS infrastructure. Links, nodes and all required attributes for the national highways, rail, air, inland and intercoastal waterways, and pipelines must be included. The fidelity, or level of attribute detail, remains to be determined. Because simulations generally require more 
network fidelity than traditional transportation models, it is likely that significant quantities of attribute data will not be available. The Supply component also provides carrier data: trucks, governmental and business automobiles and vans, locomotives and rail cars, aircraft, and water vessels. Attribute data associated with these carriers includes owner, home location, weight, dimensions, capacity, commodities carried, fuel type, fuel consumption, maximum velocity, and engine characteristics. Facility data, usually associated with network nodes, are also provided by this component. Facility data includes location, modes serviced, carrier and commodity capacities, and type and characteristics of materiel handling/switching equipment. Finally, energy resources required to run the carriers and facilities should be considered part of the Supply component. This includes primarily petroleum and electricity. These resources should not be assumed "infinitely available," as in TRANSIMS, because of the strong dependency between transportation and energy, and national level issues concerning the two.

The Supply component in figure 2 displays land use, and multiple modal networks and carriers joined together through intermodal facilities, all overlaid on energy resources. In summary, the NTS Supply component must be capable of providing the Plan and Execution components with network links, nodes, carriers, intermodal facilities, and energy resources, at appropriate levels of fidelity.

\subsubsection{Demand}

The Demand component provides the travelers and establishments with their fixed or initial locations, the commodities they own, the activities they perform, and where/when they want to move the commodities or perform their activities. NTS travelers are individuals belonging to households or group quarters (e.g., military barracks or college dormitories). Their attributes include demographic characteristics, activities to be performed, travel goals, and mode preferences. Establishments are businesses and governmental organizations with services to perform and people or commodities to be moved (i.e., business activities). Transportation demand information often comes in the form of Origin-Destination (OD) matrices with origins and destinations (by type) in the rows and columns, and quantities of people or commodities (by activity or commodity type) in the cells. The person and commodity quantities must then be disaggregated down to individuals and commodity units (e.g., tons) which are then placed at specific initial locations. It is critical that the Demand component employs methods which reduce the aggregated exogenous demand data to the level of resolution required by the Plan and Execute components.

The Demand component in figure 2 separates the activity demands of the different segments of transportation users: private and other type households, business establishments, and governmental establishments. The output of these demand modules feeds their unique trip planning functions.

Recall that demand data evolves over long time scales. As envisioned in TRANSIMS, feedback from the Plan component, in the form of unattainable travel goals, will contribute to travel demand adaptation. For example, new/aging transportation infrastructure (supply) results in activity locations being more/less accessible. This accessibility, or lack thereof, impacts various segments of the population and business community in different ways. Better accessibility provided by new infrastructures (e.g., a new intermodal facility) will encourage certain businesses to ship commodities along different routes or on different modes. Likewise, poor accessibility (e.g., to employment oppor- 
PLAN-DEMAND \& SUPPLY-DEMAND FEEDBACK:

These couplings must be included in any representation of the NTS tunities) will encourage subpopulations to change household locations to areas of better accessibility. This long term interaction can be captured in iterative feedback between the Plan and Demand components, and the Supply and Demand components. TRANSIMS has not (yet) addressed this portion of the transportation problem. Considering the many other important, shorter term issues at the metropolitan level, this representational capability has been set aside for future development. National level issues, however, are longer term in nature and more dependent on the Plan-Demand and SupplyDemand relationships. Our NTNAC will have to develop feedback methodologies fairly soon in the development process. Identification of the specific attribute or parameter values, which are critical to the coupling of these components, is the first step in this developmental process.

\subsubsection{Plan}

The Plan component generates travel plans for individual travelers, individual business establishments, and governmental organizations. These plans specify departure times, modes, use of specific intermodal sites, and arrival times. All are derived from travel goals and modal preferences. Individual travelers have unique travel goals based upon their demographic characteristics and activity requirements. Business establishment travel goals are a function of industry, location, commodity type, and profit or market share objectives. Governmental travel goals vary depending on the particular agency. Figure 2 shows separate trip planning functions for each of these user types.

Not noted on figure 2, though, are the various time delays associated with the information feedback from the Plan to the Demand component. The information passed back to the Demand component must be sent according to the user's travel planning/decision cycle. For example, household travel plans are generated daily while military travel plans are developed over much longer time periods. Consequently, households will decide quickly how well the transportation infrastructure supports their needs and change their household or employment activity locations accordingly. The military, however, does not have the ability to make such radical activity decisions so quickly (except during national emergencies). The feedback mechanisms in our NTS solution, therefore, must take these time variant planning cycles into account in order to recreate real-world, long term system evolution processes.

Many TRANSIMS researchers believe that individual traveler goals are dominated by the desire to minimize travel time. Other goals, like cost(\$), distance, and security, have been set aside despite indications from early project documents that they would be included. This issue has not yet been completely resolved. We should allow the TRANSIMS research in this area to proceed and incorporate their current conclusions concerning household travel into our NTNAC. Business travel goals are typically represented as income maximization or cost minimization. Without knowledge of proprietary income or market objectives, transportation models usually resort to travel cost minimization.

Many business travel costs (e.g., privately negotiated track usage costs between two railroads), unfortunately, are unknown. We, like other transportation modelers, will have to develop generic cost functions for each of the primary commercial modal carrier types, by commodity type, and for intermodal transfers. 


\section{FREIGHT PLANNING:}

Select a small set of fleet algorithms and modify to accomodate multiple mode choices
Most governmental travel is probably dominated by a combination of cost( $(\$)$ and travel time minimization. Our defense deployment modeling experience is that time minimization is the critical objective for the military. Heuristic search techniques like simulated annealing (which we employed in our Force Deployment Estimator model for the Joint Staff), genetic algorithms, or tabu searches can be employed in NTNAC for the military, post office, and other governmental agencies with large fleets, as well as in commercial fleet routing.

The methods that we should employ in the Plan component are efficient mode choice and route finding network based algorithms. Optimal algorithms, like the Dijkstra methods used in TRANSIMS, can continue to be used to generate individual traveler and household travel plans. Existing commercial fleet routing algorithms should be used as a starting point for our business establishment commodity trip planning. There are several in the literature and most of these are tailored for specific carrier or commodity types. We will need to do two things with respect to freight trip planning:

(1) Identify a small set of useful fleet routing algorithms that can be generalized to reasonably represent the many different types of commercial carriers and commodities. Perhaps these generic algorithms can be replaced over time by business or commodity specific algorithms but, to get an initial version of our NTNAC solution as quickly as possible, we will have to begin with generic commodity planning algorithms. A research question is, "How business or commodity specific do these mode and route planning algorithms need to be in order to generate robust national level performance indicators and other emergent behavior?"

(2) Modify the existing algorithms to incorporate mode choice. Most are single mode routing algorithms - few allow for multimodal options. The primary reason for this is that network characteristics and constraints are mode dependent. Either one must combine separate (e.g., truck fleet, rail, and air) routing schemes under one macro objective function, or new generic (almost mode independent) algorithms must be developed. The former approach is obviously computationally intensive due to the large network path solution space, but it is also more representative of real-world planning processes.

\subsubsection{Execute}

The Execute component attempts to move carriers and commodities according to the individual trip plans provided by the Plan component, within the physical constraints of the network. From a complex adaptive system representational perspective, overall system delay originates at the high fidelity, short time scales of carrier-carrier and carrierenvironment level. The planned departure times, mode and route usage, and arrival times in each travel plan are based upon assumptions concerning the transportation environment; i.e., infrastructure constraints, levels of service, and congestion. The execution of these plans either validates or invalidates these assumptions. When an assumption is invalidated, this information is fed back to the Plan component for use in the next iteration of trip planning. Figure 2 displays the trip plan input from multiple users, the information feedback to each of the user planning functions, as well as the final output for analysis. Similar to the feedback process described in the preceding section between the Plan and Demand components, the Execution feedback to the Plan component must account for the different user planning cycles. 
TRANSIMS is primarily concerned with congestion on links. Metropolitan traffic throughput (emergent behavior) is largely a function of time dependent congestion along links. In contrast, NTS links generally experience free-flow traffic conditions. Interstate freeways in the western half of the nation, and rail, river and air links are typically uncongested. There are exceptions to this. Along northeast intercity highways and during periods of environmental disasters (e.g., severe snowstorms, hurricanes, or floods like those in the midwest during 1993), national highways, railways, and waterways can become severely congested or blocked. But, overall, NTS throughput is more dependent on traffic delays at nodes, rather than along links. The Execute component, therefore, must be capable of (1) efficiently simulating free-flow traffic along links (which suggests a lower fidelity than, for example, TRANSIMS' current cellular automata approach), and (2) representing carrier-carrier and carrier-environment interactions at NTS nodes.

NTS nodes include cities, airports, seaports, truck-rail intermodal facilities, and large special attractors/generators (e.g., military bases, universities, and parks). One of the more difficult technical challenges we face is simulating the many different kinds of nodes across the nation. The Plan component can simply represent them as delay and cost functions. The Execute component,though, must represent these nodes in much more detail. For LANL to design, build, maintain separate simulations for each airport, seaport, truck-rail intermodal facility, etc. is not a task we should accept. The best approach may be a composable simulation architecture similar to that of LANL's JointSim project. In this approach to simulation development, object repositories house actors, terrain, and other environmental objects which can be selected and brought together in a single, unified architecture to compose separate simulations. This concept has particular appeal for NTS nodal simulations. For example, airport features like runways, terminals, gates, refueling trucks, and parking facilities can be represented in generic software objects and used to build any airport in the country.

Another simulation challenge, on par with simulating nodes, is representation of links that are congested. Certain national transportation issues are concerned with growing, or natural disaster induced, congestion along links. For example, the DOT has a responsibility to recommend intermodal solutions to multi-state, intercity congestion.

Throughput in these regions of the country is a function of both node and link congestion. This implies a capability to simulate links efficiently under free-flow conditions, and a capability to simulate links under more computationally intensive congested con-

NTS NETWORK FIDELITY:

Simulation network fidelity must be variable and, sometimes, dynamic ditions. In fact, the ideal simulation would have the ability to recognize when link density had reached the point at which it could influence the emergent system behavior of interest, and then alter network fidelity "on-the-fly," or dynamically. While not necessarily recommending the use of a cellular automata (CA) approach at the national level, it does demonstrate this concept of "dynamic variable fidelity." Under free-flow conditions, the size of a CA highway cell could be miles in length and the time step could have a long duration. As congestion increases, the regularly monitored ratio of volumeto-capacity $(\mathrm{V} / \mathrm{C})$ would trigger a shrinkage in cell size and a reduction in the time step. In this way the simulation could run fast and would increase it computation only when required. This dynamic capability is particularly useful for resolving node and link boundary conditions - where national highways gradually become more congested as they approach metropolitan areas. This variable, or dynamic capability, is necessary in order to integrate the hierarchy of urban and national dynamic systems (i.e., NTS and TRANSIMS' network representations). 


\subsubsection{Analysis}

The Analysis component provides the user with a "back-end" capability to observe the (virtual) NTS at any level of interest - from the transfer of truck trailers onto rail flat cars at a truck-rail intermodal facility, to system plots of annual commodity movement speeds and standard deviations. It also serves as a "front-end" to the entire NTNAC - it is the tool for designing a scenario and altering specific supply or demand attributes for "what-if" analyses. It is a set of data mining tools that can identify and display emergent system behavior as well as performance indicator values.

There is one last, but important, comment to be made concerning figure 2. The nature of the issues raised at the national level are different from those at the metropolitan levels. By their shorter term nature, many metropolitan questions require the use of the Execution component, and the output of the plan-execute-replan process. NTS issues are broader and have longer time horizons. Therefore, NTS analyses will not require the use of the Execution component as much as urban transportation analysis but, instead, will focus on the Supply-Demand-Plan end of the analytical framework.

\subsection{Application of CAS Concepts}

The NTS is a complex, adaptive socio-technical system characterized by multiple users with different goals and decision-making processes, by physical and behavorial dynamics at various spatial and temporal scales, and by embedded non-linear, stochastic processes. This is not a conjecture - it is a statement of facts. Based on these facts, it would seem reasonable to hypothesize the following:

1. Quasi-steady state and transient collective behavior is predominated by carriercarrier and carrier-facility interactions at NTS nodes and certain NTS links;

2. NTS intelligent agents are not only the individuals and households represented in TRANSIMS, but private and public establishments are intelligent agents as well. Commercial businesses, governmental agencies, and military organizations "intelligently" plan and execute trip plans, and adapt their behavior according to changing conditions;

3. NTS adaptive processes include shifts in populations and business markets due, for example, to the inability of households and businesses to satisfy their long-term personal and business goals because of inadequacies in accessibility provided by the transportation infrastructure. Similarly, shorter-term travel goals and mode preferences are subject to adaptation due to the inability to move from point $A$ to point $B$ because of congestion along transportation links, or at nodes; and

4. Simulation is required for the NTNAC in order to represent the small temporal and spatial dynamics which drive national level quasi-steady state and transient NTS performance indicators, and other emergent system behavior.

For most of the same reasons TRANSIMS adopted the CAS approach, NTS should do the same. Only when the computational burden becomes overwhelming, or a better representational approach arises, should the concepts of CAS be abandoned. 


\section{NTS RESOLUTION:}

Resolution must be at the establishment and carrier level

\subsection{Resolution, Fidelity \& Time Scale}

Important design considerations in any new model or simulation are the time scales to be addressed, and the levels of resolution and fidelity to be represented. As stated in section 4.0, TRANSIMS explicitly addresses time scales through its system partitioning, or decomposition. In this section we discuss all three design considerations with respect to the NTS.

In order to represent traffic dynamics at the causal level, and generate travel decisions at the level at which they are made, the resolution of the representation must be at the establishment and carrier level. Not to be ignored, the customer (DOT) implicitly demands individual household, business and carrier resolution based on expectations created by the TRANSIMS project.

Establishments generate travel plans while carriers are the tools by which they are carried out. The travel planning process, represented by establishment goals, modal preferences and optimization algorithms, is conducted by establishments within the Plan component. The travel execution process, represented by a variety of carriers traversing the transportation network, occurs within the Execution component - the microsimulation(s). Like TRANSIMS, we will fix the resolution at the carrier and establishment level within the Demand, Plan and Execute components.

As suggested earlier, fidelity must be variable at the NTS level. Like TRANSIMS, the Plan component requires one level of carrier and network attribute detail while the Execution component requires another, higher, level. In the current version of TRANSIMS, these two levels are fixed. Metropolitan representations appear to only require the two, fixed levels of carrier and network detail currently used within TRANSIMS' Plan and Execute components. At the national level, though, carrier and network fidelity must be varied within the Execution component. In most instances, national level links are uncongested: free flow conditions exist - very little carrier interaction occurs. Under these conditions it would be computationally inefficient to continually microsimulate at high spatial and short temporal levels. Carriers must be permitted to move greater distances in less time; i.e., at uninterupted, high velocities. There are other instances like national emergency scenarios and where national links connect to metropolitan links, where national links can quickly become congested. In these cases, our Execution component representation must be able to capture the carrier interactions. This implies a capability to vary carrier and network fidelity dynamically.

A critical modeling and analytical capability is the separation, but coupling, of the different time scales in the transportation problem. As discussed above, this is one of the primary reasons for partitioning the problem into its demand, plan and execution components. Like TRANSIMS we need long, intermediate, and short time scales. The national time scales may extend over a greater range, however. As just discussed, there are instances when we will need to microsimulate at the second-by-second carrier movement level within the Execute component. The Demand component, though, will require a longer view than TRANSIMS' metropolitan system - one of years or multiyear economic cycles - due to the nature of national level planning.

These representational capabilities imply computation - the ability to compute at various levels of complexity. Computational complexity is a function of resolution, fidelity 
and time scale. Figure 3 displays this relationship in the form of a notional 3 dimensional function. It is important to remember, though, that resolution and time scale are discrete quantities, despite the continuous scales suggested by their axes. Fidelity may be continuous depending on the algorithmic approach employed. This picture implies that computation will be greatest when resolution and fidelity are high and the time scale is short. This occurs within the Execution component when microsimulating nodes or congested links.

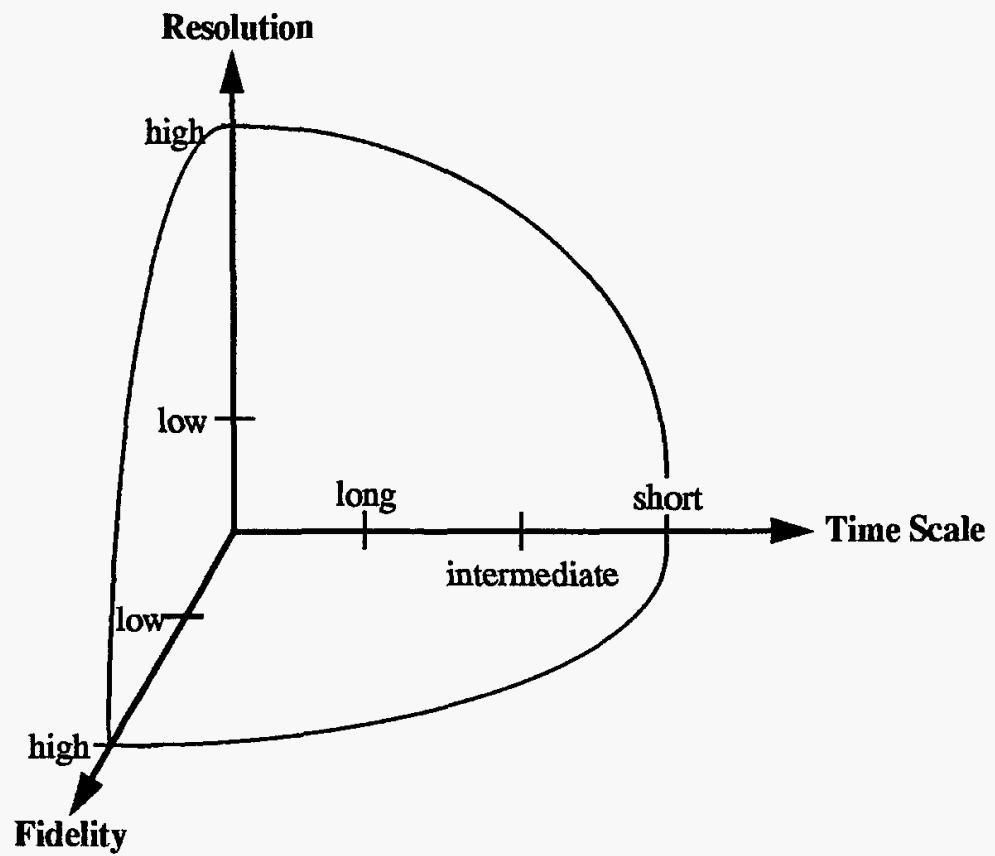

Figure 3. Computational Complexity $=\mathrm{f}$ (resolution, fidelity, time-scale)

Since many macro, long time horizon NTS issues will not require simulation, the computational complexity of the NTNAC may be less than that of TRANSIMS' metropolitan representations (due to lower network fidelity requirements and emphasis on long and intermediate time scales).

\subsection{Data}

\subsection{Requirements}

The exogenous data required to build a NTNAC that addresses national issues and NTS performance indicators discussed in section 2.5 are significant, to say the least. In fact, this has been an argument used by critics of transportation simulations for years. As discussed below, though, public source data is growing, and other private (but unclassi- 
NTS DATA

REQUIREMENTS:

Type and quantity should not be understimated -

it is enormous fied) sources are available in the interim. All of these can be used in a "TRANSIMSlike" approach rooted in simulation.

We divide external data requirements into those needed by each of the computational modules: Supply, Demand, Plan \& Execute. The Supply component, by definition, is the receiver of all exogenous transportation infrastructure data. It must format the data for use by the other components. Demand is the other component requiring a significant amount of external data. It requires aggregate household and commercial activity and census data which can be converted into individual household, and commercial and government establishment activities. The Plan and Execute components receive most of their inputs from the Supply and Demand modules, and from one another (recall the iterative feedback process between the two).

More specific data requirements for each of the components are listed below.

\subsubsection{Supply}

- national highway, rail, air, waterway and pipeline networks and attributes

with county, or lower, centroids and notional intermodal connectors (due

to the exclusion of local roads at the national level)

- major carrier sites (rail stations, airports, ports, airports, intermodal transfer sites, and commodity storage locations)

- major carrier site characteristics (person/carrier/commodity capacities, materiel handling/switching facilities, quantities and handling rates, usage costs)

- carrier inventories/fleets (business and government autos and vans, trucks, rail cars and locomotives, airplanes and jets, barges and other inland and intercoastal vessels, pipelines) by type, business establishment, and commodity carrying capability

- carrier characteristics (weight, carrying capacity in volume and tons, maximum speed, fuel consumption and other operating costs)

- land use by type and location, and regional, state, and local boundaries (e.g., NTARs, BEAs, counties, and census tracts)

- energy sources, storage and distribution facilities, and costs 


\subsubsection{Demand}

- business establishments by type (SIC, STCC or Harmonized code)

- household census data at the census tract level, or lower

- household OD (origin-destination) data at the county level, or lower (census tract level preferred)

- business establishment attributes/descriptions by SIC, STCC, or Harmonized code

- business establishment OD data at the county level, or lower

- commodity data (by SIC, STCC or Harmonized codes) by tonnage, dollar value, business establishment and business establishment area

- major carrier schedules (rail, air, and water vessel fleets)

- carrier site usage (carrier arrivals/departures, emplanements/deplanements,

- major attractor and generator locations (by type; e.g., military bases, national parks and universities)

\subsubsection{Plan}

- national highway, rail, air, waterway and pipeline networks (provided by the Supply component)

- household and business establishment OD data (provided by the Demand component)

- person, household and business establishment attribute data (provided by the Demand component)

\subsubsection{Execute}

- national highway, rail, air, waterway and pipeline networks (provided by the Supply component) 
NTS DATA

AVALABILITY:

Much data exists but significant effort is required to reconcile diverse types and formats
- individual traveller and business establishment commodity trip plans (provided by the Plan component)

- person, household and business establishment attribute data (provided by the Demand component)

\subsection{Availability}

There are many sources of data within both the public and private domains. The primary sources for national transportation data should be the Bureau of Transportation Statistics (BTS), the Bureau of Census, the Commerce Department, and other federal and state agencies because we intend our NTNAC products to be "open" - i.e., available to all federal, state and local agencies and transportation researchers. Reliance on proprietary data will only limit the use of our tools and inhibit model improvement. Until all required data becomes available, though, organizations like the American Trucking Associations. Association of American Railroads and various private data warehouses will need to be used.

The primary source for national transportation facilities is BTS's National Transportation Atlas Databases (NTAD). The current version is NTAD96. This compilation of datasets also includes political and economic boundaries. The NTAD96 includes the following data sets:

- Highway network - NHPN2

- Rail network - RAIL2M

- Air network - AIRWAY

- Water network - WATERWAY

- Highway/Rail transfer sites - AUTORAMP, TOFC

- Airports - AIRPORT

- Water ports - PORT

- States - STATE

- Counties - COUNTY

- Bureau of Ecomomic Analysis regions - BEA

- National Transportation Analysis Regions - NTAR

Note: The NTAD96 does not include a national pipeline database. 
Appendix B, Available Freight Data Bases, contains eight tables describing 35 supply and demand freight related databases. These tables describe the scope of coverage, mode type, level of geographic resolution, commodity classification, level of geographic origin-destination resolution, commodity characteristics (weight and/or value), modal equipment, system utilization, routing information, and cost data.

\subsection{Demonstration Scenario}

One of the program development commitments made in this internal LANL sponsored research was the production of a prototype NTNAC demonstration in 1998. The intent of this demonstration is to provide insight into the NTS problem, highlight algorithmic approaches, and to display a partial, but promising, NTNAC solution. The hope, of course, is that the primary target of the demonstration - the DOT - will understand the relevance of the work behind the demonstration and agree to fund further development based on its potential to satisfactorily address their national transportation issues and concerns.

In section 7.1 we outline criteria for a successful DOT demonstration. In section 7.2 we describe the scenario to be used in the demonstration. In section 7.3 we show how this scenario satisfies the criteria.

\subsection{Criteria}

The following demonstration criteria were developed on the basis of discussions with DOT, and the desire to integrate NTS and TRANSIMS research efforts.

- Relevance (to the DOT)

- Spatial Scope - larger than any single MPO's or State's area of responsibility

- Multimodalism - includes two or more modes

- Intermodalism - integrates the different modes

- Links to TRANSIMS

- Explicitly Addresses Freight

- Availability of Data

\subsection{Scenario Selection}

The scenario that most closely satisfies the criteria is what we call, "The I35 NAFTA Demo."

\subsubsection{Background}

Since the North American Free Trade Agreement (NAFTA), trade between the US and Mexico has increased. During 1996, 11,000 Mexican trucks arrived at our borders each day. Texas is the primary state of entry and departure for US-Mexico commodities. The 
Laredo border crossing alone handles $70-80 \%$ of all rail and truck traffic between the two countries. Laredo also processed 900,000 Mexican trucks during 1996.

Under the NAFTA, Mexican trucks were supposed to be allowed free access to the nation's border states of Texas, New Mexico, Arizona, and California in December 1995. Due to pressure applied by various special interest groups and the General Accounting Office, President Clinton imposed, and has maintained, a ban on this controversial open borders trucking provision. Concerns are that these trucks are too heavy, unsafe, environmentally unsound, and would hurt the American trucking industry. The trucks weigh up to 150,000 pounds - far exceeding the 80,000 pounds maximum permitted in only some US states. Safety advocates claim that Mexican trucks are three times as old as U.S. vehicles, are rarely inspected as often or as well as U.S. trucks, do not carry required insurance for operating in the U.S., and that their drivers are not required to have the same training or drug and alcohol testing. Environmentalists charge that these vehicles exceed current Clean Air Act standards. With 11,000 Mexican trucks potentially entering the U.S. each day, the Teamsters Union argues that thousands of well-paid U.S. truckers would be replaced by Mexican truckers earning as little as $\$ 7$ per day. Under the current ban, Mexican trucks are limited to border areas where their cargo is transferred to American trucks.

Supporters for lifting the ban include the governors of the border states and the American Trucking Associations (ATA). Both groups see further economic growth in the form of trucking and rail-related jobs (e.g., administration, truck stop services, equipment maintenance and software development). They also view this as an opportunity to relieve the massive congestion occuring at chokepoints like Laredo where there are a total of 10 U.S. inspectors for all 900,000 Mexican trucks, and 93 total inspectors at 23 U.S.-Mexico border crossings sites handling 4 million Mexican trucks annually.

\subsubsection{Description of Scenario}

The intent is to demonstrate the change in truck and rail traffic flow along the $\mathbf{1 3 5}$ corridor before and after the lifting of the U.S. ban on Mexican trucks. We will do this in three parts.

In part I, we will display the current locations of business establishments throughout the central U.S. at the county level. The flow of freight traffic from Laredo to Duluth, Minnesota (the northern end of I35) and Detroit, Michigan (the primary destination for Mexican goods outside of Texas and California) will be simulated as it exists today. This includes the American trucks entering, exiting and moving north and south along the full length of I35. We will also include the movement of trains generally north and south in the vicinity of $\mathrm{B35}$, and the transfer of freight at truck-rail intermodal sites. Most NTS nodes will be modeled as delay functions. One, and possibly two, nodes will be simulated in considerably more detail. Truck and rail freight will be simulated moving through the internal network of Dallas-Ft. Worth using TRANSIMS. If time and resources permit, we also hope to simulate the activity at an intermodal site located at San Antonio, or some other location between Laredo and Dallas-Ft. Worth.

In part II, we will "open the gates" and permit $2000+$, large Mexican trucks to proceed north from Laredo each day. Since I35 is the major highway between Laredo and cen- 
tral Texas, most of these trucks will proceed up this route to San Antonio and Dallas-Ft. Worth. We will display the change in traffic flows, particularly between Laredo and Dallas-Ft. Worth. We will also "zoom-in" on Dallas-Ft. Worth and show, in much greater detail, the effect these trucks are having on this urban area's internal traffic again, using TRANSIMS.

In part III, we will demonstrate one alternative for relieving the increased demand on I35 - an additional, or improved, truck-rail intermodal facility between Laredo and San Antonio. The idea is to show the possible changes, both good and bad, of transferring freight from the Mexican trucks to U.S. rail. This would reduce the number of trucks entering Dallas-Ft. Worth, and increase the number turning around and heading back to Mexico.

\subsubsection{Criteria Satisfaction}

Relevance. This issue is relevant for numerous reasons. If the Mexican trucks are released into the U.S. border states, transportation planners at all levels will have to manage rapid changes in supply and demand. At one end of the national transportation issues scale is the impact these trucks will have on the local areas and border states. Local congestion, incident (safety) management, and air quality issues all must be considered by both local planners and national policy makers. While they are primarily local and state concerns, the fact that the entire southwestern part of the country is affected makes it a national transportation issue as well. At the other end of the scale are the macro issues of overall NTS efficiency, support of economic development and trade flows, congested intercity traffic, and intermodal improvements. DOT must address the impact this significant change in north-south traffic demand will have on the overall efficiency of the NTS. Infrastucture changes like upgrades of north-south interstate highways (primarily I35) and the addition of truck-rail intermodal facilities adjacent to these interstates are just a few of the supply changes that must be examined. The relevancy of this scenario was also confirmed when we spoke with DOT. They were enthusiastic and willing to support our efforts (although not financially - yet).

Spatial Scope. The spatial coverage of this scenario is beyond that of any single MPO or state - it is at the national level. Although the focus of the scenario is along $\mathbf{1 3 5}$ from Laredo to Dallas-Ft. Worth, we will demonstrate the ability to generate the county level freight demand and resulting traffic flow all along the 135 corridor from Mexico to Canada.

Multimodalism. The ability to seamlessly integrate different modes is very important to DOT and their understanding of the NTS. Transportation users view the system as one system comprised of many modal opportunities and plan their travel accordingly. The use of both trucks and rail to move freight satisfies this criterion.

Intermodalism. This criterion is closely tied to multimodalism - you cannot have intermodal trips without having multiple modes, and facilities to connect the modes. Intermodalism is emphasized in ISTEA and is a priority of the DOT. The generation of trip plans that considers the time and monetary costs associated with shipping commodities through truck-rail intermodal facilities satisfies this criterion. The addition of a simulation of one specific intermodal facility would further enhance the demonstration. 
Links to TRANSIMS. It is important to DOT that the TRANSIMS and NTNAC representations are integratable. As it does in the real world, the NTS must link to the metropolitan areas. By building a scenario that includes Dallas-Ft. Worth, we can directly incorporate data, models, and the simulation from TRANSIMS' recent Dallas case study. Dallas-Ft. Worth is one node in the NTS. Along with the possible simulation of one intermodal facility, we will demonstrate linkage to both a TRANSIMS node and one other detailed NTS node.

Explicitly Addresses Freight. Freight movement analysis is an area that is receiving increasing attention within the transportation community. There are few methods for characterizing and explaining how freight moves - the best algorithms, tools, and data are owned by individual firms are proprietary and predominately unimodal. In addition, this is an area that TRANSIMS needs to address. By choosing a scenario with freight as the focus, we can address current analytical concerns within DOT and leverage research efforts with the TRANSIMS team.

Availability of Data. There is a minimum set of real-world input data that is required to produce a believable demonstration. This data set consists of a near-complete network of links and nodes for each mode, business establishments by commodity type and (approximate) location, carriers by type and other relevant attributes, and demand data in the form of commodity origins an destinations is required. This minimum data set (for freight, and highway and rail modes) is available for the scenario.

\subsection{Summary}

Our examination of the Department of Transportation's National Transportation System (NTS) Initiative and a National Transportation Network Analysis Capability (NTNAC) was conducted during the last two months of FY 1997. The objectives of the effort were to:

1. Define the NTS problem;

2. Identify problem characteristics;

3. Describe an analytical solution based on a "TRANSIMS-like" approach;

4. Identify data requirements and availability;

5. Develop criteria for a scenario to be used in a prototype demonstration; and

6. Select a scenario for the demonstration.

In the words of the DOT, the NTS problem is simply this, 
The Department still does not have the ability to view and analyze the Nation's transportation system in its entirety as a single integrated, intermodal system.

In the DOT's initial problem solving efforts, they identified critical national transportation issues and system performance indicators. These issues are broad - they range from concerns about truck weights to transportation support of national economic development. Like many of the issues, more than half of the $40+$ NTS performance indicators require some form of dynamic systems analysis. Due to the nature of the issues and indicators, and the inherent structure of the NTS, we have identified the DOT's national level analysis problems as falling into one of the following problem, or analysis, classes:

- Steady State,

- Quasi-Steady State, or

- Transient.

Any NTNAC solution must be capable of addressing questions requiring these types of system analyses. This leads us to conclude that the principle objective of the NTNAC must be the representation of dynamic intermodal movement of goods and people across the nation.

If one defines a "TRANSIMS-like" approach to the NTS problem as (1) adopting TRANSIMS' analytical decomposition of large scale transportation system dynamics, and (2) representing the transportation system as a CAS, then, yes, the TRANSIMS approach is directly applicable to the NTS problem. In fact, the NTS is a hierarchical CAS with complex adaptive urban transportation systems present at every metropolitan node within the national network.

There are differences, though. Urban and national transportation systems lead to difficult technical issues - e.g., the multitude and diversity of simulations required for the NTS, the need for dynamic network fidelity, and intermodal routing algorithms involving highway, heavy rail, air, and water carriers owned and scheduled by a wide range of establishments with different trip planning concerns; and this is even before addressing the distinctly unique pipeline system. They each require significant research efforts but, in our opinion, they can all be resolved.

Finally, the internal LANL research proposal for this project established a prototype NTNAC demonstration as a primary objective for 1998 . We have identified a scenario for this demonstration, called the "I35 NAFTA Demo," which satisfies joint DOT and LANL criteria for a successful program development demonstration. In our opinion, however, the funding provided for FY 1998 will not provide the resources required to gather and process the necessary data, research and implement demand disaggregation and intermodal routing algorithms, and develop the prototype software required to satisfy the expectations of the DOT within one year. If a primary objective of the 1998 research effort is to secure external funding, and an "I35 NAFTA Demo" is necessary to do this, then additional resources are required.

The next step in the project, the first phase of our FY 1998 efforts, is to research critical algorithms for the Plan and Demand components. Much work has been done to solve 
the Vehicle Routing Problem - the problem of assigning routes to multiple vehicles, with multiple destinations, all originating from a central location (depot), and at minimum cost without violating vehicle capacities. For our Plan component we will either need to modify certain existing algorithms (to accomodate intermodalism, multiple commodity types, and many shippers and depots), or develop new approaches altogether. The other area of research involves the demand-plan adaptation process. As discussed in this report, the shorter time scale plan-execute adaptive process influences the longer time scale demand-plan process. This Demand-Plan coupling has not been tested in TRANSIMS, but is crucial to many of the national level issues the NTNAC must address. After these areas are understood, the focus of our FY98 efforts will be to pull all of the data and algorithms together into a coherent NTS representation and prototype demonstration. 


\subsection{References}

1987 Standard Industrial Classification Manual, Office of Management and Budget.

A Guidebook for Forecasting Freight Transportation Demand, National Cooperative Highway Research Program Report 388, Transportation Research Board, National Academy Press, Washington DC, 1997.

A Model for the Strategic Planning of National Freight Transportation by Rail, T. Crainic, et.al., Transportation Science, Vol. 24, No. 1, Feb 90.

A Network Flow Heuristic for Bulk Routing, Transportation Science, Vol. 29, No. 1, Feb 95.

An Outline of TRANSIMS' Activity \& Intermodal Route Planner, Los Alamos National Laboratory Technical Report LA-UR-95-2697, D. Anson, April 1995.

A Progress Report on The National Transportation Initiative, US Department of Transportation, Dec 1996.

Arc Routing Problems, Part 1: The Chinese Postman Problem, Operations Research, Vol. 43, No. 2, Mar-Apr 95.

Assessment of Border Crossings and Transportation Corridors for North American Trade - Report to Congres Pursuant to the Intermodal Surface Transportation Efficiency Act of 1991, Federal Highway Administration, Wash DC, Sep 93.

Complexity: Metaphors, Models, and Reality, Proceedings Volume XIX from the Santa Fe Institute's Studies in the Sciences of Complexity, Addison-Wesley Publishing Company, Reading, MA, 1994.

Development of Data and Analysis Tools in Support of a National Intermodal Network Analysis Capability, F. Southworth, Oak Ridge National Laboratory, TN, 1997.

Emergence, Hierarchies, and Hyperstructures, Artificial Life III, Santa Fe Institute Studies in the Sciences of Complexity, Proceedings Vol. XVII, Addison-Wesley, 1994.

Force Deployment Estimator (FDE) Model, Los Alamos National Laboratory Technical Report LACP 94-176, D. Anson et. al., June 1994.

Implementing Vehicle Routing Models, Transportation Research B, Vol. 24B, No. 4, 1990.

Implications of Intermodal Freight Movements for Infrastructure Access, Capacity, and Productivity, Department of Transportation report DOT-VNTSC-RS667-PM-96-11, prepared by Volpe National Transportation Systems Center for the FHWA, March 1996.

Intermodal Freight Transportation, 3rd Edition, Gerhardt Muller, Eno Transportation Foundation, Inc., Lansdowne, VA, 1995. 
Inside DOT \& Transportation Week, Department of Transportation, February 7, 1997.

Inside DOT \& Transportation Week, Department of Transportation, April 17, 1997.

Inside DOT \& Transportation Week, Department of Transportation, May 23, 1997.

Intermodal Technical Assistance for Transportation Planners and Policymakers, Office of Intermodalism, Department of Transportation, Wash DC, Dec 94.

JointSim - A Foundation for Simulation Research, draft of a white paper prepared by LANL, August 1997.

Mobility Analysis and Requirements Simulation System (MARSS), Proposal submitted to the Advanced Research Project Agency, BAA 95-30/Area2, Los Alamos National Laboratory, Sep 95.

National Transportation System Performance Measures - Final Report, Department of Transportion report DOT-T-97-04, prepared by Cambridge Systematics for the Office of the Secretary of the US Department of Transportation, April 1996.

New Transportation Concepts For a New Century: AASHTO Recommendations on the Direction of the Future Federal Surface Transportation Program and for a National Transportation Policy, American Association of State Highway and Transportation Officials, Wash DC, Oct 89.

NTS Meeting Among DOT, BTS and LANL, held at DOT Headquarters, Sep 11, 1997.

Report on the National Transportation Network Analysis Workshop, DOT-T-97-05, Arlington VA, September 6-7, 1995, Sponsored by the Department of Transportation.

Seeing the Light at El Farol - A Look at the Most Important Problem in Complex Systems Theory, John L. Casti, Complexity,John Wiley \& Sons, 1996.

Solving a General Routing and Scheduling Problem, Transportation Science, Vol. 29. No. 1, Feb 95.

Strategic Planning of Freight Transportation in Brazil: Methodology and Applications, Edited by T. Crainic and M. Florian, University of Montreal, 1989.

The General Pickup and Delivery Problem, Transportation Science, Vol. 29, No. 1, Feb 95.

The Past and Future of the Sciences of Complexity, Melanie Mitchell, 1997 Stanislaw Ulam Memorial Lecture Series, Sep 97.

Traffic Flow Fundamentals, Adolf D. May, Prentice Hall Publishers, New Jersey, 1990.

TRANSIMS Model Design Criteria as Derived from Federal Legislation, J. Morrison and V. Loose, Los Alamos National Laboratory Technical Report LAUR 95-1909, June 12, 1995. 
Urban Transportation Planning: A Decision-Oriented Approach, M. Meyer and E. Miller, McGraw-Hill, Inc., New York, 1984.

World Wide Web and the Demise of the Clockwork Universe, The X Journal, Vol. 4, No. 5, May-Jun 95. 


\subsection{Appendix A. Averaging and The Limitations it Generates}

To investigate the limitations imposed by averaging, write a general expression for a transient scalar quantity that is position dependent. In a transportation sense, this might be a measure of traffic density for example. Vector quantities could also be considered but we will limit ourselves to scalar information within this discussion. We can expand this representation in terms of dependencies. The identification of these dependencies may arise from observation or physical laws that are expected to capture behavior. For example, traffic density, $\rho$, might be a function of population density and manufacturing density. We will denote these as $P$ and $M$ respectively so that

$$
\rho=\rho(t, P, M) .
$$

The commonly used steady-state representation of Eq. (1) is denoted by

$$
\rho=\rho(P, M) .
$$

\subsection{The Meaning of "Transient"}

To investigate transient conditions, differentiate Eq. (1) with respect to time

$$
\frac{d \rho}{d t}=\frac{\partial \rho}{\partial t}+\left(\frac{\partial \rho}{\partial P}\right)\left(\frac{d P}{d t}\right)+\left(\frac{\partial \rho}{\partial M}\right)\left(\frac{d M}{d t}\right)
$$

where the independent variables are assumed to be time dependent. Equation (3) yields 3 cases, or classes, of problems that can be denoted as

1. Steady-state where $\frac{d \rho}{d t}=0$ because $\frac{\partial \rho}{\partial t}=\frac{d P}{d t}=\frac{d M}{d t}=0$.

2. Quasi-steady where $\frac{\partial \rho}{\partial t} \cong 0$ so that $\frac{d \rho}{d t}=\left(\frac{\partial \rho}{\partial P}\right)\left(\frac{d P}{d t}\right)+\left(\frac{\partial \rho}{\partial M}\right)\left(\frac{d M}{d t}\right)$

This condition can be determined using steady-state characteristics, $\left(\frac{\partial \rho}{\partial P}\right)$ and

$\left(\frac{\partial \rho}{\partial M}\right)$, obtained from Eq. (2) and the growth rates for population and manufacturing as denoted by $\left(\frac{d P}{d t}\right)$ and $\left(\frac{d M}{d t}\right)$. 
3. Transient where $\frac{\partial \rho}{\partial t} \neq 0$ so that Eqs. (1) and (3) apply. This condition also means that $\left(\frac{\partial \rho}{\partial P}\right)$ and $\left(\frac{\partial \rho}{\partial M}\right)$ are each instantaneous quantities, i.e. dependent on the instant in time they are determined. Thus, each different transient most likely requires a different transient relationship. This presents a complex situation that is difficult to analyze mathematically. In this case, heuristic representations as that noted by Eq. (1) are of little use and a transient simulation that captures the fundamental physics of the process in question is required.

From this perspective, it is easy to understand the desire to apply the quasi-steady or steady-state analysis approach to any process. Determining when this approach is valid requires determining when $\frac{\partial \rho}{\partial t} \cong 0$. Insight into this question can be obtained by looking at how the steady-state traffic density relationship denoted by Eq. (2) is obtained.

\subsection{Steady or Quasi-steady Models}

Information is often time or ensemble averaged to minimize the effects of random variations or to capture the "average" behavior. By collecting data from a number of different locations or cities, each having different conditions, the relationship denoted by Eq. (2) may be obtained. Thus, the time average traffic density can be written as

$$
\bar{\rho}=\left(\frac{1}{\Delta t}\right) \int_{\Delta t} \rho(u, P, M) d u,
$$

where $u$ is the dummy of integration. Now we wish to consider the arguements made in the previous section where $\rho$ is replaced with the time averaged quantity $\bar{\rho}$.

The requirement placed on this time average is that the interval $\Delta t$ must be chosen long enough that minor changes in the length of this time interval do not further change the average. For example, assume a day represents the time required to repeat a fundamental cycle in the process. If $\Delta t_{p}$ represents this controlling time period and $\mathrm{n}_{0}$ the minimal number of occurrences (cycles) required to produce an average insensitive to time, the minimum time for a statistically sufficient sample can be written as $\Delta \mathrm{t}_{\min }=\mathrm{n}_{0} \Delta t_{p}$. If the time of interest in the simulation is greater than this minimum time, use of the time-averaged traffic density is valid. This insensitivity can be observed from the fact that if the time interval over which averaging is done were increased by some arbitrary amount of time $\delta \mathrm{t}$, no change should be observed in the average value so that

$$
\int_{\left(\Delta t_{\min }+\delta t\right)} \rho(u, P, M) d u=\int_{\Delta l_{\min }} \rho(u, P, M) d u
$$

Hence, it can be concluded that 


$$
\frac{\partial}{\partial t} \bar{\rho}=\lim _{(\delta t \rightarrow 0)}\left(\frac{1}{\delta t}\right)\left\{\int_{\left(\Delta t_{\min }+\delta t\right)} \rho(u, P, M) d u-\int_{\Delta t_{\min }} \rho(u, P, M) d u\right\}=0 .
$$

This property is one of the characteristics of a stationary process. In effect this implies that Eq. (2) should have been written as

$$
\bar{\rho}=\bar{\rho}(P, M)
$$

with similar changes to Eq. (3) and the discussion that followed.

If the solution time frame desired is less than $\Delta \mathrm{t}_{\min }$ then $\bar{\rho}$ will reflect a sensitivity to time resulting from the averaging process. To analyze times shorter than $\Delta t_{\min }$, the traffic density must be known with respect to its individual controlling phenomenon and on a time scale less than $\Delta t_{p}$.

\subsection{Spatial Averaging}

Spatial averaging requirements similar to those for temporal issues discussed above can be obtained and Eq. (1) might have been written as

$$
\rho=\rho(t, \vec{x}, P, M),
$$

where $t$ represents the local vector position. Spatial averaging relaxes the local characterization represented by $\vec{x}$. For brevity, those will not be presented here.Appendix B.

Data Tables 


\subsection{Appendix B. Available Freight Data Bases}

This appendix consists of eight tables describing 35 supply and demand freight related databases. These tables list the scope of coverage, mode type, level of geographic resolution, commodity classification, level of geographic origin-destination resolution, commodity characteristics (weight and/or value), modal equipment, system utilization, routing information, and cost data. 
Table B.1: Scope of Freight Databases

Database

Scope Or Coverage

1993 Commodity Flow Survey (CFS)

TRANSEARCH (Reebie)

Freight Transportation and Logistics Service (DRIMH)

U.S. Imports/Exports of Merchandise on CD-ROM

U.S. Exports by State of Origin (Census)

U.S. Exports by State of Origin (MISER)

U.S Exports and Imports Transshipped via Canadian Ports

The Directory of U.S. Importers/Exporters

National Transportation Statistics Annual Report

U.S. Air Freight Origin Traffic Statistics (Colography)

U.S. Air Carrier Traffic and Capacity (T-1OO) Data

FAA Airport Activity Statistics (T-3)

Worldwide (North American) Airport Traffic Report (ACT)

ICC Carload Waybill Sample *

Freight Commodity Statistics (MR)

North American Trucking Survey (NATS)

LTL Commodity and Market Flow Database

Truck Irventory and Use Survey (TIUS)

Nationwide Truck Activity and Commodity Survey (NTACS)

Port Import/Export Reporting Service (PIERS)

U.S. Waterbome General and Intransit Shipments

Waterborne Commerce and Vessel Statistics (ACOE) *

Ship Movements Database (Lloyd's)

World Sea Trade Service (DRLMH)

Lock Performance Monitoring System (PMS) *

St. Lawrence Seaway Traffic Reports

Lake Carriers' Association Annual Report

Exports from Manufacturing Establishments

Fresh Fruit and Vegetable Shipments

Fresh Fruit and Vegetable Arrival Totals for 23 Cities

Quarterly Coal Report

Natural Gas Monthly

Natural Gas Annual

Petroleum Supply Monthly

Grain Transportation Report

* Public Use Data Only

\section{2 of 49}

Development of An Analysis Capability for The National Transportation System

Originating shipments in U.S. mamufacturing, mining, wholesale and selected retail and service establishments Traffic between 183 BEAs compiled from several sounces

Regional commodity traffic by barge, rail and truck compiled from several sounces

Quantity and value of merchandise shipped between U.S. and foreign countries; weight for air and vessel Vaine of U.S. exports for all mode8s weight for air and vessel

Value of U.S. exports for all modes; weight for air and vessel

Value and weight of U.S. imports and exports to foreiga countries via Canadian ports

Listing Of U.S. companles engaged in international trade; total traffic shown when available

Activity and industry statistic: by mode

Weight, value and number of air cargo shipments for selected top U.S. producing industries

Airport-to-airport domestic air freight tonnage for reporting U.S. carriers

Airport air freight enplaned weight for reporting U.S. cities

Air freight weight for ACI-mernber airports

Sample of all rail waybills for movements terminating On U.S. railroads moeting reporting standard

All commodity traffic for U.S. Class I railnoads

Truck stop sample of truck weights; predominantly long-haul truckload carers

Weight, mumber Of shipments, and number Of pieces by traffic lane for participating carriers

Sample of trucks (including pickops and vans) registered in each state

Sample Of daily/weekly activity for trucks (including pickups and vans) registered in each state

International waterborne shipments entering or exiting U.S. ports (excluding some small-volume ports)

Value and weight of waterbone trade between U.S. and foreign ports; low value shipments are estimated Weight and vessel trips for all domestic and waterbonre movements on U.S. waterways or via U.S. ports

Vessel movements on international trade. routes as reported principal world ports

Weight and containerloads for ocean traffic on over 700 major world trade routes

Activity at locks owned or operated by the U.S. Army Corps Of Engineers

Weight and muber of vessel transits on the St. Lawrence Seaway

Weight and mumber of vessel oa the Great Lakes reported by ICA members

Export value and related employment for all U.S. manufacturing establishments

Fresh fruit and vegetable weight by month collected from various sources

Fresh fruit and vegetable weight for 23 U.S. and 4 Canadian cities estimated from various sources

Weight Of coal ship. by aN U.S. companies which own, purchase, or distribute 50,000 tons per year

Shipment activity for all generating eloctric utilities and a sarmple of companles delivering natural gas to consumers

Activity for an companies that deliver to consumers, handle interstate movements, or are licensed to import/export

Shipment actlvity by survey of U.S. refiners, blenders, plant operators, transporters, and importers

Grain traffic and carloads compiled from various sources 
Table B.2: Mode, Type, and Structure of Freight Databases

Data Base Mode

\begin{tabular}{|c|c|c|}
\hline & Mode & \\
\hline 1993 Cormmodity Flow Survey (CFS) & $\bar{M}$ & Shipment - True O/D \\
\hline TRANSEARCH (Recbie) & $\mathbf{M}$ & Shipment - True $O / D$ \\
\hline Freight Transportation and Logistics Service (DRU/MH) & $\mathbf{M}$ & Transport - Modal Profile \\
\hline U.S. Imports/Exports of Merchandise on CD-ROM & $\mathbf{M}$ & Shipment - Modal O/D \\
\hline U.S. Exports by State of Origin (Census) & $\mathbf{M}$ & Shipment - True O/D \\
\hline U.S. Exports by State of Origin (MISER) & $\mathbf{M}$ & Shipment - True O/D \\
\hline U.S Exports and Imports Transshipped via Canadian Ports & $\mathbf{M}$ & Shipment - Modal O/D \\
\hline The Directory of U.S. Importers/Exporters & $\mathbf{M}$ & Other - Origin Activity \\
\hline National Transportation Statistics Annual Report & $\mathbf{M}$ & Transport -Modal Profile \\
\hline U.S. Air Freight Origin Traffic Statistics (Colography) & A & Other - Origin Activity \\
\hline U.S. Air Carrier Traffic and Capacity (T-1OO) Data & $\mathbf{A}$ & Transport $-O / D$ \\
\hline FAA Airport Activity Statistics (T-3) & $\mathbf{A}$ & Transport - Point Activity \\
\hline Worldwide (North American) Airport Traffic Report (ACI) & $\mathbf{A}$ & Transport -Point Activity \\
\hline ICC Carload Waybill Sample * & $\mathbf{R}$ & Shipment - Modal O/D \\
\hline Freight Commodity Statistics (MR) & $\mathbf{R}$ & Transport - Modal Profile \\
\hline North American Trucking Survey (NATS) & $\mathbf{T}$ & Shipment - Modal True O/D \\
\hline LTL Commodity and Market Flow Database & $\mathbf{T}$ & Shipment - Modal True O/D \\
\hline Truck Inventory and Use Survey (TIUS) & $\mathbf{T}$ & Transport - Carrier Profile \\
\hline Nationwide Truck Activity and Commodity Survey (NTACS) & $\mathbf{T}$ & Transport -Carrier Profile \\
\hline Port lmport/Export Reporting Service (PIERS) & $\mathbf{W}$ & Shipment - Modal O/D \\
\hline U.S. Waterbome General and Intransit Shipments & $\mathbf{W}$ & Transport - O/D \\
\hline Waterborne Commerce and Vessel Statistics (ACOE) * & W & Transport - Point/Sub-system Activity \\
\hline Ship Movements Database (Lloyd's) & $\mathbf{W}$ & Transport - O/D \\
\hline World Sea Trade Service (DRI/MH) & $\mathbf{W}$ & Transport - O/D \\
\hline Lock Performance Monitoring System (PMS) * & w & Transport - Point Activity \\
\hline St. Lawrence Seaway Traffic Reports & w & Transport - Sub-system Activity \\
\hline Lake Carriers' Association Annual Report & $\mathbf{w}$ & Transport - Point Activity \\
\hline Exports from Manufacturing Establishments & $\overline{\mathbf{N}}$ & Other - Origin Activity \\
\hline Fresh Fruit and Vegetable Shipments & MC & Other - Origin Activity \\
\hline Fresh Fruit and Vegetable Arrival Totals for 23 Cities & MC & Transport - O/D \\
\hline Quarterly Coal Report & MC & Other - O/D Activity \\
\hline Natural Gas Monthly & MC & Other - O/D Activity \\
\hline Natural Gas Annual & MC & Other - O/D Activity \\
\hline Petroleum Supply Monthly & MC & Transport - O/D \\
\hline Grain Transportation Report & MC & Other - Commodity Profile \\
\hline
\end{tabular}

Level of Detail

NTAR-NTAR Combinations

BEA-BEA Combinations

National/Regional Aggregates

Country-U.S. Customs District Combinations

State-Country Combinations

State-Country Combinations

Country-U.S. Custons District Combinations

Company

National Aggregates

U.S. County

Airport-Airport Combinations

Airport

Airport

BEA-BEA Combinations

Regional Aggregates

City-City Combinations

ZIIP-ZIP3 Combinations

Vehicle

Vehicle

Port-Port (Some Shipper/Consigneo Locations)

Port-Port Combinations

Port/Waterway Segment

Vessel Trip (Port-Port)

Coastal Range-Coastal Range Combinations

Waterway Lock

Waterway Segment

Origin Port or Lake

State

State/Country

State-City Combinations.

State/Country Combinations

State/Country Combinations

State/Country Combinations

Region-Region (State) Combinations

Coastal Range/Lock
Domeatic/International

Not Identified

Not Identified

Not Identified

International

International

International

International

International

Not Identified

Domestic \& Int

Not Identified

Not Identified

Domestic \& Inti.

Domestic \& Intl.

Not Identified

Not Identified

Domestic \& Intl

Not Identified

Not Identified

International

International

Domestic \& Intl.

International

International

Not Identified

Domestic \& Intl.

Not Identified

International

Domestic \& Intl.

Domestic \& Intl.

Domestic \& Intl.

Domestic \& Intl.

Domestic \& Intl.

Not Identified

Not Identified or Intl.

* Public Use Data Only Modes: $M=$ Multimodal, $A=A$ Air, $R=$ Rail, $T=$ Truck, $W=$ Water, $M C=$ Multimodal Commodity specific 
Table B.3: Commodity Information in Freight Databases

\begin{tabular}{|c|c|c|c|c|c|}
\hline \multirow[b]{2}{*}{ Databage } & \multicolumn{3}{|c|}{ Commodity Classification (Level of Detai) } & \multirow[b]{2}{*}{ Other } & \multirow[b]{2}{*}{ Comments } \\
\hline & Product & Producer & Transport & & \\
\hline 1993 Commodity Flow Survey (CFS) & & & $\operatorname{STCC}(5)$ & Hazmat & STCC (5) for National, STCC(3) for NTAR-NTAR \\
\hline TRANSEARCH (Reebie) & & & $\operatorname{sTCC}(4 / 5)$ & & Detail dependent on mode \\
\hline Freight Transportation and Logistics Service (DRL/MH) & & & STCC & & \\
\hline U.S. Imports/Exports of Merchandise on CD-ROM & HS (10), SITC (5) & $\operatorname{SIC}(4)$ & & End User (4) & \\
\hline U.S. Exports by State of Origin (Census) & SITC (4) & $\operatorname{SIC}(2)$ & & & \\
\hline U.S. Exports by State of Origin (MISER) & & SIC (2) & & & \\
\hline U.S Exports and Imports Transshipped via Canadian Ports & HS (4) & & & & \\
\hline The Directory of U.S. Importers/Exporters & HS (10), Dese. & & & & \\
\hline \multicolumn{6}{|l|}{ National Transportation Statistics Annual Report } \\
\hline U.S. Air Freight Origin Traffic Statistics (Colography) & & SIC (4) & & Size & Shipment-size categories possible (e.g., Express, Heavy) \\
\hline U.S. Air Carrier Traffic and Capacity (T-100) Data & & & & Size/Piority & Shipment-size categories possible (e.g., Priority/Non-Priority) \\
\hline FAA Airport Activity Statistics (T-3) & & & & Size/Priority & Shipment-size categories possible (e.g., Priority/Non-Priority) \\
\hline Worldwide (North American) Airport Traffic Report (ACI) & & & & Size Group & Size: Freight, Mail \\
\hline ICC Carload Waybill Sample * & & & $\operatorname{STCC~(5)~}$ & Hazmat & \\
\hline Freight Commodity Statistics (MR) & & & $\operatorname{sTCC}(5)$ & & \\
\hline North American Trucking Survey (NATS) & & & $\operatorname{STCC}(3)$ & & \\
\hline LTL Cornmodity and Market Flow Database & & & & Service & Service: Standard/Non-Standard, Special Equipment \\
\hline Truck Inventory and Use Survey (TIUS) & & & TIUS & Hazmat & Survey Classifications \\
\hline Nationwide Truck Activity and Commodity Survey (NTACS) & & & TIUS & Harmat & Survey Classifications \\
\hline Port lmport/Export Reporting Service (MIERS) & HS (10), PIERS & & & & PIERS groups: Full manifest description also available \\
\hline U.S. Waterbome General and Intransit Shipments & HS (10), SITC & & & & \\
\hline Waterborne Conmerce and Vessel Statistics (ACOE) * & & & CCDWC & & \\
\hline \multicolumn{6}{|l|}{ Ship Movements Database (Lloyd's) } \\
\hline World Sea Trade Service (DRIMH) & SITC Groups & & & & Specialized SITC groupings \\
\hline Lock Performance Monitoring System (PMS) * & & & PMS (2) & & Corps-developed groups \\
\hline St. Lawrence Seaway Traffic Reports & Special Groups & & & Toll-Based & \\
\hline Lake Carriers' Association Annual Report & Special Groups & & & & Bulk Groups, Petroleum, Grains \\
\hline Exports from Manufacturing Establishments & & $\operatorname{SIC}(3)$ & & & \\
\hline Fresh Fruit and Vegetable Shipments & Dese. & & & & Some grouping for bow volume or mixed commodities \\
\hline Fresh Fruit and Vegetable Arrival Totals for 23 Cities & Desc. & & & & Some grouping for low volume or mixed commodities \\
\hline Quarterly Coal Report & Dese. & & & & Some commodity breakdown for physical characteristics \\
\hline Natural Gas Monthly & Desc. & & & & \\
\hline Natural Gas Annual & Desc. & & & & \\
\hline Petroleum Supply Monthly & Desc. & & & & \\
\hline Grain Transportation Report & Specisl Groups & & & & Total grains: wheat, corn and soybeans \\
\hline
\end{tabular}

44 of $49 \quad$ STCC $=$ Standard Transportation Cmmodity Code, CCDWC $=$ Commodity Classification for Domestic Waterbome Commerce 
Table B.4: Origin/Destination Information in Freight Databases

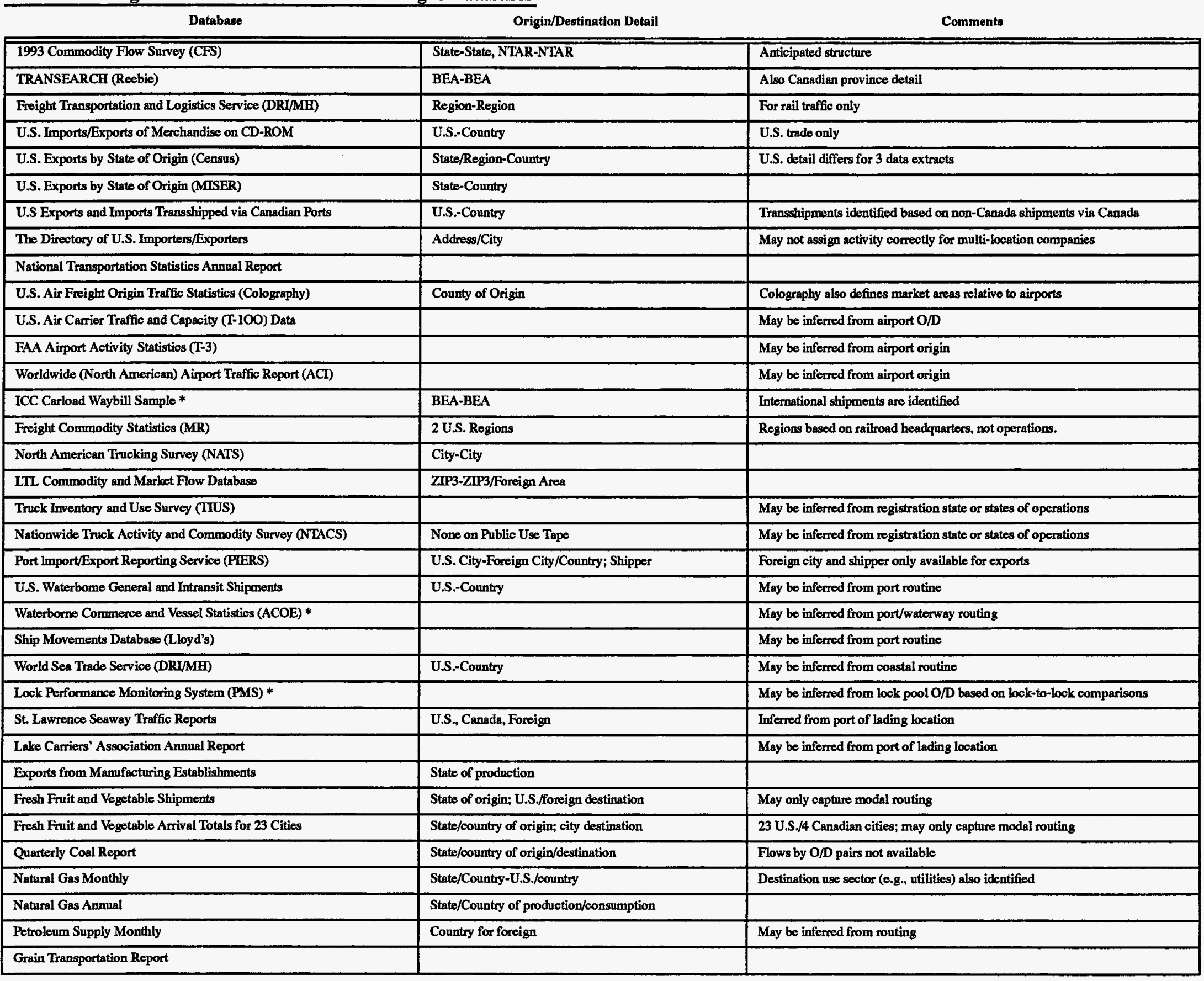

* Public Use Data Only NTAR = Nationa Transportation Analysis Region, BEA = Bureau of Economic Analysis Region, Zip3 = 3 digit U.S. Zip Code 
$\mathcal{K}_{[0}$

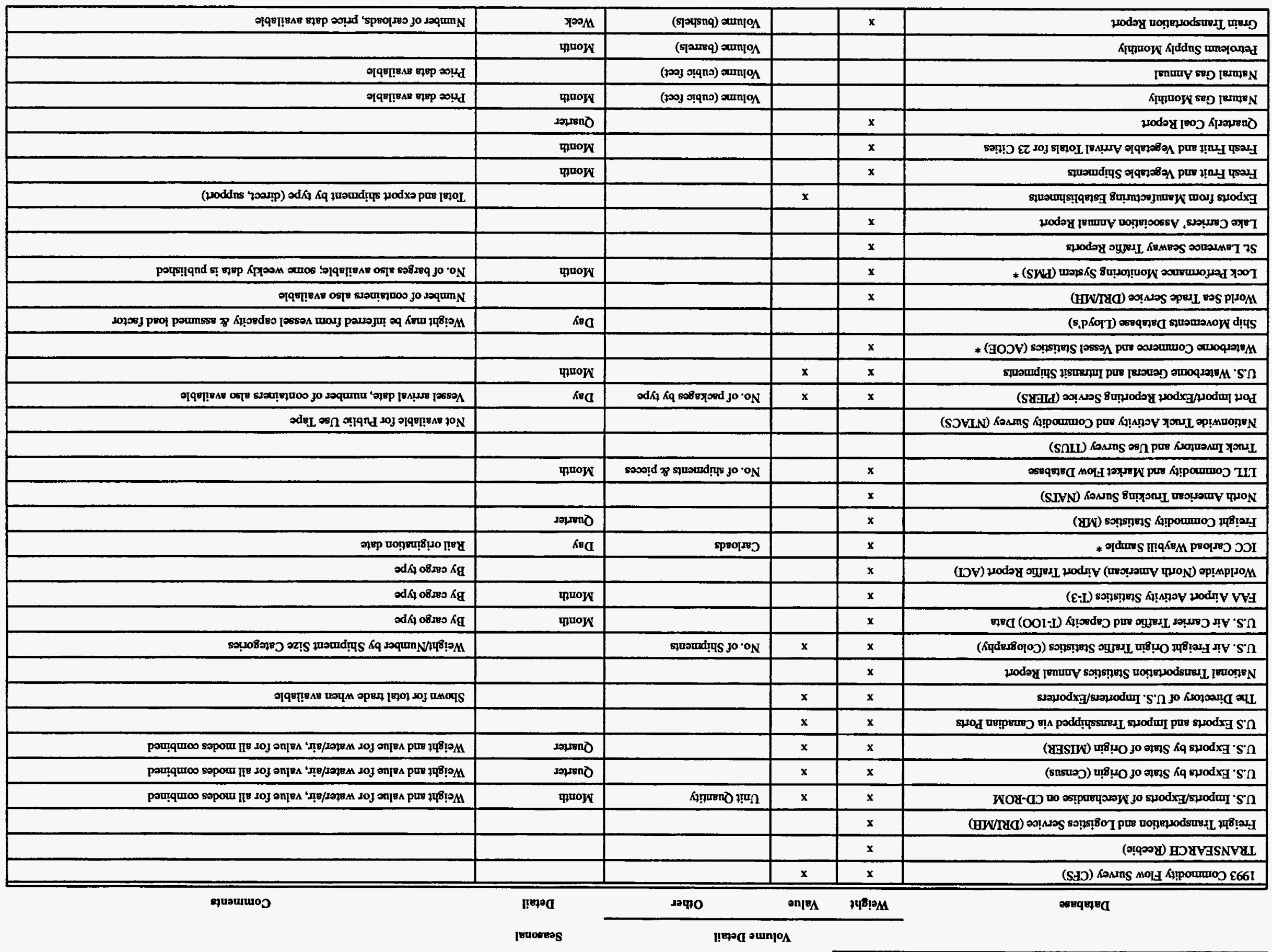


Table B.6: Information on Modal Coverage and Equipment in Freight Databases

\begin{tabular}{|c|c|c|c|c|c|c|c|c|c|}
\hline \multirow[b]{2}{*}{ Database } & \multicolumn{6}{|c|}{ Modal Coverage } & \multirow[b]{2}{*}{ Other } & \multicolumn{2}{|c|}{ Equipment } \\
\hline & $\mathbf{A}$ & $\mathbf{T}$ & $\mathbf{R}$ & $\mathbf{I W}$ & 0 & All & & Intermodal & Other \\
\hline 1993 Commodity Flow Survey (CFS) & $\mathbf{x}$ & $\mathbf{x}$ & $\bar{x}$ & $\mathbf{x}$ & $\mathbf{x}$ & & Pipeline, parcel & Container Weight & \\
\hline TRANSEARCH (Reebie) & $\mathbf{x}$ & $\mathbf{x}$ & $\bar{x}$ & $x$ & $\mathbf{x}$ & & & No.of Containers & No.ofUnits by mode \\
\hline Freight Transportation and Logistics Service (DRI/MH) & & $\mathbf{x}$ & $\mathbf{x}$ & $\mathbf{x}$ & & & & & Unit trafficfleet size by mode \\
\hline U.S. Imports/Exports of Merchandise on CD-ROM & $\mathbf{x}$ & & & & $x$ & $\mathrm{x}$ & & Container Weight (vessel) & \\
\hline U.S. Exports by State of Origin (Census) & $\mathbf{x}$ & & & & $\mathbf{x}$ & $\mathbf{x}$ & & Container Weight (vessel) & \\
\hline U.S. Exports by State of Origin (MISER) & $\mathbf{x}$ & & & & $\mathbf{x}$ & $\mathbf{x}$ & & Container Weight (vessel) & \\
\hline U.S Exports and Imports Transshipped via Canadian Ports & & & & & & & Surface total & & \\
\hline The Directory of U.S. Importers/Exporters & & & & & & & List of modes & & \\
\hline National Transportation Statistics Annual Report & $\mathbf{x}$ & $\mathbf{x}$ & $\mathbf{x}$ & $\bar{x}$ & $\mathbf{x}$ & & Pipeline, parcel & & Vehicle inventory \\
\hline U.S. Air Freight Origin Traffic Statistics (Colography) & $\mathbf{x}$ & & & & & & & & \\
\hline U.S. Air Carrier Traffic and Capacity (T-100) Data & $\mathbf{x}$ & & & & & & & & Aircraft departures by equipment type \\
\hline FAA Airport Activity Statistics (T-3) & $\mathbf{x}$ & & & & & & & & Aircraft departures by equipment type \\
\hline Worldwide (North American) Airport Traffic Report (ACI) & $\mathbf{x}$ & & & & & & & & Aircraft operations by type \\
\hline ICC Carload Waybill Sample * & & & $\mathbf{x}$ & & & & & No.of trailers/containers & car type \\
\hline Freight Commodity Statistics (MR) & & & $\mathbf{x}$ & & & & & & \\
\hline North American Trucking Survey (NATS) & & $\mathbf{x}$ & & & & & & & trailer type \\
\hline LTL Commodity and Market Flow Database & & $\mathbf{x}$ & & & & & & Identified & Special equipment use identified \\
\hline Truck Irventory and Use Survey (TIUS) & & $\mathbf{x}$ & & & & & & & Vehicle type/configuration \\
\hline Nationwide Truck Activity and Commodity Survey (NTACS) & & $\mathbf{x}$ & & & & & & & Vehicle type/configuration \\
\hline Port Import/Export Reporting Service (PIERS) & & & & & $\mathbf{x}$ & & & Container no., size and volume & Vessel name \\
\hline U.S. Waterbome General and Intransit Shipments & & & & & $\mathbf{x}$ & & & & Tanker Identified \\
\hline Waterborne Commerce and Vessel Statistics (ACOE *) & & & & & $\mathbf{x}$ & & & & \\
\hline Ship Movements Database (Lloyd's) & & & & & $\mathbf{x}$ & & & & Vessel name \\
\hline World Sea Trade Service (DRI/MH) & & & & & $\mathbf{x}$ & & & Containerloads & Vessel type/size categories \\
\hline Lock Perfornance Monitoring System (PMS) * & & & $\mathbf{x}$ & & & & & & Tow, barge type and size \\
\hline St. Lawrence Seaway Traffic Reports & & & $x$ & & & & & Container Weight & Vessel type, class and size category \\
\hline Lake Carriers' Association Annual Report & & & $\mathbf{x}$ & & & & & & \\
\hline Exports from Mamufacturing Establishments & & & & & & $\mathbf{x}$ & & & \\
\hline Fresh Fruit and Vegetable Shipments & $\mathbf{x}$ & $\mathbf{x}$ & $\mathbf{x}$ & & $\mathbf{x}$ & $\mathbf{x}$ & & Piggyback Identified & \\
\hline Fresh Fruit and Vegetable Arrival Totals for 23 Cities & $\mathbf{x}$ & $\mathbf{x}$ & $\mathbf{x}$ & & $\bar{x}$ & $\mathrm{x}$ & & & \\
\hline Quarterly Coal Report & $\mathbf{x}$ & $\mathbf{x}$ & $\mathbf{x}$ & & $\mathbf{x}$ & & Slurry & & \\
\hline Natural Gas Monthly & & & & & $x$ & & Pipeline & & \\
\hline Natural Gas Annual & & & & & $\mathbf{x}$ & & Pipeline & & \\
\hline Petroleum Supply Monthly & & & & $\bar{x}$ & $x$ & & Pipeline & & \\
\hline Grain Transportation Report & & & $\mathbf{x}$ & $\mathbf{x}$ & $\mathbf{x}$ & & & & Rail carloadings, barge, export ship calls \\
\hline
\end{tabular}

* Public Use Data Only $\quad A=A i r, T=$ Truck, $R=$ Rail, IW = Inland Waterway/Coastal, $0=$ Other Water, All = Combines All Modes 
Table B.7: Information on System Use in Freight Databases

\begin{tabular}{|c|}
\hline Database \\
\hline 1993 Commodity Flow Survey (CFS) \\
\hline TRANSEARCH (Reebie) \\
\hline Freight Transportation and I Logistics Service (DRI/MH) \\
\hline U.S. Imports/Exports of Merchandise on CD-ROM \\
\hline U.S. Exports by State of Origin (Census) \\
\hline U.S. Exports by State of Origin (MISER) \\
\hline U.S Exports and Imports Transshipped via Canadian Ports \\
\hline The Directory of U.S. Importers/Exporters \\
\hline National Transportation StatisticslAnmual Report \\
\hline U.S. Air Freight Origin Traffic Statistics (Colography) \\
\hline U.S. Air Carrier Traffic and Capacity (T-100) Data \\
\hline FAA Airport Activity Statistics (T-3) \\
\hline Worldwide (North American) Airport Traffic Report (ACI) \\
\hline ICC Carload Waybill Sample* \\
\hline Freight Commodity Statistics (MR) \\
\hline North American Trucking Survey (NATS) \\
\hline LTL Commodity and Market Flow Database \\
\hline Truck Irventory and Use Survey (TIUS) \\
\hline Nationwide Truck Activity and Commodity Survey (NTACS) \\
\hline Port Import/Export Reporting Service (PIERS) \\
\hline U.S. Waterborne General and Intransit Shipments \\
\hline Waterborme Commerce and Vessel Statistics (ACOE)* \\
\hline Ship Movements Database (Lloyd's) \\
\hline World Sea Trade Service (DRI/MH) \\
\hline Lock Performance Monitoring System (PMS) * \\
\hline St. Lawrence Seaway Traffic Reports \\
\hline Lake Carriers' Association Annual Report \\
\hline Exports from Manufacturing Estsblishments \\
\hline Fresh Fruit and Vegetsble Shipments \\
\hline Fresh Fruit and Vegetable Arrival Totals for 23 Cities \\
\hline Quarterly Coal Report \\
\hline Natural Gas Monthly \\
\hline Natural Gas Annual \\
\hline Petroleum Supply Monthly \\
\hline Grain Transportation Report \\
\hline
\end{tabular}

\begin{tabular}{|c|c|}
\hline \multicolumn{2}{|c|}{ System Utilization } \\
\hline Point & SubSystem \\
\hline \multirow[t]{2}{*}{ Port of exit: wgt. } & O/D Corridor Ton-miles, wgt. \\
\hline & O/D Corridor \\
\hline Customs District: wgt., val., qty. & Modal Route: tons, value, qty. \\
\hline \multirow[t]{2}{*}{ Customs District/Port: wgt, val. } & O/D-Port: wgt, val. \\
\hline & O/D: wgt, val. \\
\hline \multicolumn{2}{|l|}{ Customs District/Port: wgt., val. } \\
\hline & Modal total: Vehicle-, ton-miles \\
\hline Airport: wgt. & Modal Route: wgt, ton-miles \\
\hline \multicolumn{2}{|l|}{ Airport of emplanement/departure } \\
\hline \multicolumn{2}{|l|}{ Airport of emplanement/departure } \\
\hline & Modal Route: wgt, ton-miles, carloads \\
\hline & Modal Total: wgt, carloads \\
\hline \multicolumn{2}{|l|}{ City: O/D wgt. } \\
\hline \multirow[t]{3}{*}{ City: O/D wgt, \# of shpmts./pieces } & Modal Route: wgt, ton-miles, shpmts.piocess \\
\hline & Modal Total: vehicle-miles \\
\hline & Modal Route: vehicle-miles, operating wecks \\
\hline City, Country, Port: wgt, val., packages & Modal Route: wgt, val. \\
\hline Port: wgt, val. & Modal Route: wgt., val. \\
\hline Port: wgt., ton-miles & Waterway: wgt, ton-miles \\
\hline Port: vessel calls, capscity & Modal Route: capacity \\
\hline Coastal: wgt, containerloads & Modal Route: wgt., containerloads \\
\hline \multicolumn{2}{|l|}{ Lock: wgt, barges, tows } \\
\hline & Waterway: wgt, vessel GRT, transits \\
\hline \multirow[t]{3}{*}{ Port: wgt, vessel calls, shipments } & Modal Route: wgt., vessel calls, shipments \\
\hline & Modal Route: wgt. \\
\hline & Modal Route: wgt. \\
\hline \multicolumn{2}{|l|}{ Customs District/Port: wgt, val. } \\
\hline & Pipeline: volume \\
\hline & Modal Route: volume \\
\hline & Coast, Lock: wgt., units \\
\hline
\end{tabular}

* Public Use Data Only 
Table B.8: Information on Routing, Carrier, and Cost in Freight Databases

\begin{tabular}{|c|c|c|c|c|}
\hline \multirow[b]{2}{*}{ Database } & \multicolumn{2}{|c|}{ Round } & \multirow{2}{*}{$\begin{array}{l}\text { Carrier/ } \\
\text { Service }\end{array}$} & \multirow{2}{*}{$\begin{array}{l}\text { Cost/ } \\
\text { Rate }\end{array}$} \\
\hline & Definition & Distance & & \\
\hline 1993 Commodity Flow Survey (CFS) & Port of exit for exports & Estimate of $\mathrm{O} / \mathrm{D}$ Mode & & \\
\hline \multicolumn{5}{|l|}{ TRANSEARCH (Reebie) } \\
\hline Freight Transportation and Logistics Service (DRI/MH) & & & & Modal profiles \\
\hline U.S. Imports/Exports of Merchandise on CD-ROM & Customs District & & & Import freight charges \\
\hline U.S. Exports by State of Origin (Census) & Customs District/Port & & & \\
\hline \multicolumn{5}{|l|}{ U.S. Exports by State of Origin (MISER) } \\
\hline U.S Exports and Imports Transshipped via Canadian Ports & Customs District & & & \\
\hline The Directory of U.S. Importers/Exporters & List of Ports & Avg. length of haul & & \\
\hline National Transportation Statistics Annual Report & & & Shipment size groupings (e.g. express) & \\
\hline U.S. Air Freight Origin Traffic Statistics (Colography) & Domestic/Export & & Carrier & \\
\hline U.S. Air Camier Traffic and Capacity (T-100) Data & Airport-Airport Segments & Segment miles (estimate) & Scheduled/non-scheduled & \\
\hline FAA Airport Activity Statistics (T-3) & Airport of emplanement & & & \\
\hline Worldwide (North American) Airport Traffic Report (ACI) & Airport of enplanement & & & Carrier revenue \\
\hline ICC Carrier Waybill Sample * & BEA O/D; Interchange states & Short line miles (estimate) & & Carrier revenue \\
\hline \multicolumn{5}{|l|}{ Freight Commodity Statistics (MR) } \\
\hline North American Trucking Survey (NATS) & City-CIty & & & \\
\hline LTL Commodity and Market Flow Database & ZIP3-ZIP3 & From ton miles & Standard/non-standard & Revenue \\
\hline Truck Inventory and Use Survey (TIUS) & Intra-/extra-state activity & & & \\
\hline Nationwide Truck Activity and Commodity Survey (NTACS) & No. of states, highway type & Annual & & \\
\hline Port Import/Export Reporting Service (PIERS) & City-City/Country via Ports & & Carrier & \\
\hline U.S. Waterbome General and Intransit Shipments & Port-Port & & Liner, non-liner, tanker & Import freight charges \\
\hline Waterborne Commerce and Vessel Statistics (ACOE) * & Waterway-Waterway & From ton miles & & \\
\hline Ship Movements Database (Lloyd's) & Port-Port & & Carrier name & \\
\hline World Sea Trade Service (DRI/MF) & Coast-Const & & Liner/non-liner & \\
\hline Lock Performance Monitoring System (PMS) * & Lock & & & \\
\hline St. Lawrence Seaway Traffic Reports & Waterway Sections & & Flag of carrier & Revenue \\
\hline Lake Carriers' Association Amnual Report & Intra-lake Port-Port & & Flag of carrier & \\
\hline Exports from Manufacturing Establishments & & & & \\
\hline Fresh Fruit and Vegetable Shipments & State/country origin - dom./Intl. & & & \\
\hline Fresh Fruit and Vegetable Arrival Totals for 23 Cities & & & & \\
\hline Quarterly Coal Report & Customs Distriet (Intl. only) & & & \\
\hline Natural Gas Monthly & Pipeline company & & Pipeline company & Company financiers \\
\hline Natural Gas Annual & & & & \\
\hline Petroleum Supply Mouthly & U.S. Region-Region & & & \\
\hline Grain Transportation Report & U.S. export coast; river lock & & & Ship charter rates \\
\hline
\end{tabular}

* Public Use Data Only

Development of An Analysis Capability for The National Transportation System 49 


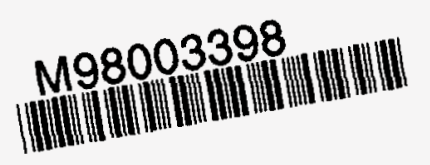

Report Number (14) $\angle A-U R--4389$

Publ. Date (11) $\frac{19971024}{D O E / M A, X F}$
Sponsor Code (18)
UC Category (19) 